\title{
OPEN Stellate cell computational modeling predicts signal filtering in the molecular layer circuit of cerebellum
}

\author{
Martina Francesca Rizza ${ }^{1}$, Francesca Locatelli ${ }^{1}$, Stefano Masoli ${ }^{1}$, Diana Sánchez-Ponce ${ }^{3}$, \\ Alberto Muñoz ${ }^{3,4}$, Francesca Prestori ${ }^{1,5}$ \& Egidio D'Angelo ${ }^{1,2,5 \bowtie}$
}

The functional properties of cerebellar stellate cells and the way they regulate molecular layer activity are still unclear. We have measured stellate cells electroresponsiveness and their activation by parallel fiber bursts. Stellate cells showed intrinsic pacemaking, along with characteristic responses to depolarization and hyperpolarization, and showed a marked short-term facilitation during repetitive parallel fiber transmission. Spikes were emitted after a lag and only at high frequency, making stellate cells to operate as delay-high-pass filters. A detailed computational model summarizing these physiological properties allowed to explore different functional configurations of the parallel fiber-stellate cell-Purkinje cell circuit. Simulations showed that, following parallel fiber stimulation, Purkinje cells almost linearly increased their response with input frequency, but such an increase was inhibited by stellate cells, which leveled the Purkinje cell gain curve to its $4 \mathrm{~Hz}$ value. When reciprocal inhibitory connections between stellate cells were activated, the control of stellate cells over Purkinje cell discharge was maintained only at very high frequencies. These simulations thus predict a new role for stellate cells, which could endow the molecular layer with low-pass and band-pass filtering properties regulating Purkinje cell gain and, along with this, also burst delay and the burst-pause responses pattern.

The stellate cells (SCs) are inhibitory interneurons of the cerebellum molecular layer (ML) that were first identified in histological preparations by $\mathrm{Golgi}^{1}$ and $\mathrm{Cajal}^{2,3}$. Electrophysiological recordings in vivo ${ }^{4,5}$ revealed their inhibitory nature. Since then, several observations have been reported on SC morphology ${ }^{6,7}$ and molecular properties $^{8-21}$, but the way SCs control cerebellar functioning remained elusive. One of the reasons is that isolating the contribution of SCs from that of other microcircuit elements (especially the basket cells) is experimentally impractical leaving several functional hypotheses undetermined. To face the issue, we have measured SCs electroresponsiveness and their activation by parallel fiber (PF) bursts with the aim of generating precise models, which had then been used to explore the computational impact of these neurons on Purkinje cells (PCs).

SCs populate the outer two thirds of the cerebellum ML and provide inhibition to PCs. Their dendrites are organized isotropically around the soma and lay on the parasagittal plane, where they are intercalated with the surrounding PC dendrites. The axon travels a short distance along the transverse plane, following the PFs, and terminates with inhibitory synapses on PC dendrites as well as on other SCs generating feed-forward inhibition ${ }^{5,8-11}$. Several studies have suggested that, in combination with the direct excitatory pathway provided by PF-PC synapses, feed-forward inhibition may assure effective motor performance ${ }^{9,12-15}$ and learning ${ }^{16,22}$. Inhibition provided by molecular layer interneurons (MLI) proved also able to regulate the bandwidth of PC responses in spots and beams ${ }^{17,18}$. Despite the importance of SCs, there is little knowledge on their mechanisms of action [for a recent review $\operatorname{see}^{20}$ ].

The electrophysiological properties of SCs have been identified only in part. SCs fire spontaneously in the $1-35 \mathrm{~Hz}$ range, both in vitro and in vivo ${ }^{8,23,24}$. The firing rate is dynamically regulated by several ionic channels, including T-type $\mathrm{Ca}^{2+}$ channels and A-type $\mathrm{K}^{+}$channels ${ }^{25,26}$. Evidence has also been provided about the receptors

\footnotetext{
${ }^{1}$ Department of Brain and Behavioral Sciences, University of Pavia, Via Forlanini 6, 27100 Pavia, Italy. ${ }^{2}$ Brain Connectivity Center, IRCCS Mondino Foundation, Pavia, Italy. ${ }^{3}$ Centro de Tecnología Biomédica (CTB), Technical University of Madrid, Madrid, Spain. ${ }^{4}$ Departamento de Biología Celular, Complutense University of Madrid, Madrid, Spain. ${ }^{5}$ These authors jointly supervised this work: Francesca Prestori and Egidio D'Angelo. ${ }^{\square}$ email: dangelo@unipv.it
} 
and currents involved in synaptic transmission ${ }^{27}$. Given that a full characterization of all the relevant mechanisms is unavailable at the moment, a first hypothesis on stellate cell role could be generated through computational modeling, which can synthesize morpho-electrical information in a coherent rule-based framework (e.g. see the case of granule cell ( $\mathrm{GrC}$ ), Golgi cells and PCs, just to remain in the cerebellum) ${ }^{28-35}$.

Initial attempts at modeling ML functions involved simplified representations of MLI. Those models have shown the impact of increasing or decreasing SC transmission strength under the assumption of linear rate coding and in the absence of short-term plasticity ${ }^{36,37}$. However, it is now clear from several studies that detailed membrane and synaptic dynamics are critical to understand the way a neural circuit operates ${ }^{38,39}$. Therefore, we have recorded electroresponsive and synaptic dynamics of SC and used them to generate detailed computational models through well-defined workflows for model construction and validation ${ }^{34,35,40}$. The models, based on accurate morphologies and membrane mechanisms, faithfully reproduced the whole set of available experimental data. Importantly, a marked short-term facilitation at PF-SC synapses, as well as inhibitory transmission from other SCs, proved to be instrumental to modulate SC response curves to input bursts. The SC properties reverberated onto the PCs generating low-pass and band-pass filtering of PF signals ${ }^{41}$. These observations imply that SCs transform the ML in a filter that limits the response bandwidth of on-beam PCs into the low-frequency range, leading to new hypotheses on how the cerebellar cortex processes incoming signals.

\section{Methods}

Electrophysiological recordings. All experiments were conducted in accordance with European guidelines for the care and use of laboratory animals (Council Directive 2010/63/EU) and approved by the Ethical Committee of Italian Ministry of Health (628/2017-PR). We performed whole-cell patch-clamp recordings (WCR) from SCs in acute cerebellar slices from P18-P25 male and female C57/BL6 mice. Briefly, mice were killed by decapitation after deep anesthesia with halothane (Sigma-Aldrich). The cerebellum was gently removed, and the vermis was isolated and fixed on the stage of a vibroslicer with cyanoacrylic glue. Acute 220 - $\mu$ m-thick slices were cut in the coronal plane in a cold $\left(2-3^{\circ} \mathrm{C}\right)$ oxygenated bicarbonate-buffered saline solution (Kreb's solution) and maintained at room temperature for at least $1 \mathrm{~h}$, before being transferred to a recording chamber. The slices were continuously perfused at a rate of $1.5 \mathrm{ml} / \mathrm{min}$ with oxygenated Kreb's solution and maintained at $32^{\circ} \mathrm{C}$ with a Peltier feedback device (TC-324B, Warner Instrument). The Kreb's solution contained the following (in $\mathrm{mM}$ ): $\mathrm{NaCl} 120, \mathrm{KCl} 2, \mathrm{MgSO}_{4} 1.2, \mathrm{NaHCO}_{3} 26, \mathrm{KH}_{2} \mathrm{PO}_{4} 1.2, \mathrm{CaCl}_{2}$ 2, glucose 11 ( $\mathrm{pH} 7.4$ when equilibrated with $\left.95 \% \mathrm{O}_{2}-5 \% \mathrm{CO}_{2}\right)$. SR 95,531 (gabazine; $10 \mu \mathrm{M}$, Abcam) and strycnine $(1 \mu \mathrm{M}, \mathrm{Abcam})$ were added to the bath solution in order to block inhibitory synaptic inputs. Slices were visualized in an upright epifluorescence microscope (Axioskop 2 FS, Zeiss) equipped with $a \times 63,0.9$ NA water-immersion objective. Patch pipettes were fabricated from thick-walled borosilicate glass capillaries (Sutter Instruments) by means of a Sutter P-1000 horizontal puller (Sutter Instruments). Recordings were performed using a Multiclamp 700B [- $3 \mathrm{~dB}$; cutoff frequency (fc), $10 \mathrm{kHz}$ ], sampled with Digidata 1550 interface, and analyzed off-line with pClamp10 software (Molecular Devices). SCs were recorded in the outer two-thirds of the molecular layer, where they are the only neuronal species present ${ }^{6,42}$.

PF stimulation was performed with a large-bore patch pipette filled with Kreb's solution and placed across the molecular layer $\sim 200 \mu \mathrm{m}$ from the recording electrode. The stimulus intensity ranged from 10 to $50 \mathrm{~V}$ with duration of $0.2 \mathrm{~ms}$. In order to analyze short-term dynamics during repetitive stimulation, trains of 10-20 pulses @ 50, 100 and $200 \mathrm{~Hz}$ were applied.

All data are reported as mean \pm SEM. Means were compared by a Student's $t$-test or by one-way parametric analysis of variance (ANOVA). Where appropriate, data were further assessed by conducting the Tukey post hoc test. The analysis was two-sided, with level of significance $\alpha=0.05$.

Whole-cell recording properties. The stability of WCR can be influenced by modification of series resistance $\left(R_{s}\right)$. To ensure that $R_{s}$ remained stable during recordings, passive electrode-cell parameters were monitored throughout the experiments. In each recording, once in the whole-cell configuration, the current transients elicited by $10 \mathrm{mV}$ hyperpolarizing pulses from the holding potential of $-70 \mathrm{mV}$ in voltage-clamp mode showed a biexponential relaxation. Membrane capacitance $\left(\mathrm{C}_{\mathrm{m}}=6.7 \pm 0.5 \mathrm{pF} ; \mathrm{n}=23\right)$ was measured from the capacitive charge (the area underlying current transients) and series resistance $\left(\mathrm{R}_{\mathrm{s}}=27.1 \pm 3.1 \mathrm{M} \Omega ; \mathrm{n}=23\right)$ was calculated as $\mathrm{R}_{\mathrm{s}}=\tau_{\mathrm{VC}} / \mathrm{C}_{\mathrm{m}}$. The input resistance $\left(\mathrm{R}_{\mathrm{In}}=1.3 \pm 0.1 \mathrm{G} \Omega ; \mathrm{n}=23\right)$ was computed from the steady-state current flowing after termination of the transient. The $3-\mathrm{dB}$ cutoff frequency of the electrode-cell system, $f_{\mathrm{VC}}(1.2 \pm 0.1$; $\mathrm{n}=23$ ), was calculated as $f_{\mathrm{VC}}=\left(2 \pi \cdot 2 \tau_{\mathrm{VC}}\right)^{-1}$. Series resistance was constantly monitored throughout the experiment. In analyzed recording periods, $\mathrm{R}_{\mathrm{s}}$ was constant within $20 \%$.

Stellate cell excitability. Pipette had a resistance of 7-10 $\mathrm{M} \Omega$ before seal formation with a filling solution containing the following (in $\mathrm{mM}$ ): potassium gluconate $126, \mathrm{NaCl} 4$, HEPES 5, glucose $15, \mathrm{MgSO}_{4} \cdot 7 \mathrm{H}_{2} \mathrm{O} 1$, BAPTA-free 0.1, BAPTA-Ca ${ }^{2+} 0.05, \mathrm{Mg}^{2+}$-ATP 3, $\mathrm{Na}^{+}$-GTP 0.1, pH adjusted to 7.2 with $\mathrm{KOH}$. Just after obtaining the cell-attached configuration, electrode capacitance was carefully cancelled to allow for electronic compensation of pipette charging during subsequent current-clamp recordings. After switching to current clamp, intrinsic excitability was investigated by setting the holding current at $0 \mathrm{pA}$ and injecting $2 \mathrm{~s}$ steps of current (from - 16 to $20 \mathrm{pA}$ in a $4 \mathrm{pA}$ increment). Action potential threshold $\left(\mathrm{AP}_{\text {thr }}\right)$ was measured along the rising phase of membrane potential responses to step current injections. The $\mathrm{AP}_{\text {thr }}$ was identified at the flexus starting the regenerative process (a procedure that was improved by taking the second derivative of membrane potential). Action potential duration at half amplitude, half-width, $\left(\mathrm{AP}_{\mathrm{HW}}\right)$ was measured at the midpoint between the threshold and the peak. The amplitude of the action potential $\left(\mathrm{AP}_{\mathrm{Ampl}}\right)$ was estimated as the difference between the threshold and the maximum reached potential. The amplitude of the action potential afterhyperpolariza- 
tion $\left(\mathrm{AP}_{\mathrm{AHP}}\right)$ was estimated as the difference between threshold and the lowest potential after the peak. Action potential frequency $\left(\mathrm{AP}_{\text {Freq }}\right)$ was measured by dividing the number of spikes by step duration and spike times were used to calculate interspike intervals (ISI). Peri-stimulus time histograms (PSTHs) were constructed for the analysis of responses to $100 \mathrm{~Hz}-10$ pulses stimulation. To optimize PSTH resolution, a $40 \mathrm{~ms}$ bin width was used.

Synaptic currents. Pipette had a resistance of 4-6 $\mathrm{M} \Omega$ before seal formation with a filling solution containing the following (in $\mathrm{mM}$ ): $81 \mathrm{Cs}_{2} \mathrm{SO}_{4}, 4 \mathrm{NaCl}, 2 \mathrm{MgSO}_{4}, 1 \mathrm{QX}-314$ (lidocaine $N$-ethyl bromide), 0.1 BAPTA-free, 0.05 BAPTA-Ca ${ }^{2+}, 15$ glucose, $3 \mathrm{Mg}^{2+}$-ATP, $0.1 \mathrm{Na}^{+}$-GTP and 15 HEPES, pH adjusted to 7.2 with CsOH. SCs were voltage-clamped at $-70 \mathrm{mV}$. The EPSC , were elicited at three types of high-frequency trains (20 pulses@ 50,100 and $200 \mathrm{~Hz}$ ). Each train stimulation sweep was separated from the preceding one by at least $30 \mathrm{~s}$. EPSC amplitude value was calculated as the difference between peak and base. The facilitation during the repetitive stimulation was computed, for each $\Delta t$, by normalizing the amplitudes to the first EPSC.

Tissue preparation for morphological reconstructions. For morphological reconstruction of MLI, adult C57/BL6 adult mice ( 8 weeks) were used. They received an overdose of sodium pentobarbital ( $0.09 \mathrm{mg} / \mathrm{g}$, i.p.) and were perfused transcardially with phosphate-buffered saline $(0.1 \mathrm{M} \mathrm{PBS})$ followed by $4 \%$ paraformaldehyde in $0.1 \mathrm{M} \mathrm{PB}$. Their brains were then removed and postfixed in $4 \%$ paraformaldehyde for 24 h. Vibratome parasagittal sections $(200 \mu \mathrm{m})$ of the cerebellum were obtained. Sections were prelabeled with 4 , 6-diamidino2-phenylindole (DAPI; Sigma, St Louis, MO), and a continuous current was used to inject with Lucifer yellow ( $8 \%$ in 0.1 ; Tris buffer, $\mathrm{pH} 7.4$; LY) individual cells at different distances from the pial surface in the ML of the cerebellum. Following the intracellular injections, sections were processed for immunofluorescence staining. They were incubated for $72 \mathrm{~h}$ at $4{ }^{\circ} \mathrm{C}$ in stock solution (2\% bovine serum albumin, $1 \%$ Triton X-100, and 5\% sucrose in PB) containing rabbit anti-LY (1:400,000; generated at the Cajal Institute, CSIC, Spain). The sections were then rinsed in PB and incubated in biotinylated donkey anti-rabbit IgG (1:100; Amersham, Buckinghamshire, United Kingdom). Then, sections were then rinsed again and incubated with Alexa fluor 488 streptavidinconjugated (1:1000; Molecular Probes, Eugene, OR, United States of America). Finally, the sections were washed and mounted with ProLong Gold Antifade Reagent (Invitrogen Corporation, Carlsbad, CA, USA).

For cell reconstruction and quantitative analysis, sections were imaged with a confocal scanning laser attached to a fluorescence microscope Zeiss (LSM710). Consecutive stacks of images at high magnification ( $\times 63$ glycerol; voxel size, $0.057 \times 0.057 \times 0.14 \mu^{3}$ for mouse cells) were acquired to capture dendritic, and in some cases also axonal, arbors on the basis of Lucifer yellow immunostaining.

Data points of neuron morphology of each ML interneuron were extracted in 3D using Neurolucida 360 (MicroBrightfield). Briefly, dendrites, axon and soma, in the skeleton definition were described through 3D points delimiting the different segments that form the cell arbor. These points have an associated diameter that provides the information of the varying thickness of the dendritic or axonal processes and varies along the length of the processes. The soma was defined through a set of connected points tracing the contour of the soma in 2D. Morphological variables were extracted using Neurolucida software.

Computational modeling. In this work, we have constructed and simulated multi-compartment SC models, using Python-NEURON (Python 2.7.15; NEURON 7.7) ${ }^{43}$. The models were based on four mouse SC detailed morphologies. The ionic channels were distributed over the somatic, dendritic and axonal compartments, according to immunohistochemical, electrophysiological and pharmacological data, and modeled following the $\mathrm{HH}$ formulation or Markov-chains for multi-state transitions, using mathematical methods reported previously $^{30-33,44}$ (see Fig. 1).

The models were optimized with BluePyOpt ${ }^{45}$. At the end of the optimization process the models are provided by the fine interaction of 14 ionic channels for a total of 36 maximum ionic conductances $\left(G_{i-\max }\right)$ parameters assigned in the different morphology sections (Supplementary Figs. 1-2 and Table 1). $\mathrm{G}_{\mathrm{i} \text {-max }}$ parameters have been found by an automatic optimization procedure to obtain the ensemble of electrophysiological behaviours. Each channel needed a precise value of $\mathrm{G}_{\mathrm{i} \text {-max }}$ to interact, in an optimal way, with all the other values to achieve the exact balance between the sophisticated ionic channel dynamics.

Morphology and synaptic location. Four mice stellate neurons were chosen from fluorescent images obtained with a confocal microscope and reconstructed with Neurolucida 360. The morphologies consisted of branched dendritic trees, a soma, and a branched axon with collaterals (the axon is short and unmyelinated). The table (Supplementary Table 2) shows the number of morphological compartments along with their diameter and length. The location of the inhibitory synapses on PCs was derived from available anatomo-physiological data. The PC dendrites are divided into three orders of branching receiving specific synaptic inputs (cf. ${ }^{28}$ ). Concerning excitatory synapses, branch II received only PF synapses and branch III received only ascending axon synapses $^{14,15,46}$. Inhibitory synapses were distributed only on branches I and II for a total of 221 sections, since branches III were experimentally reported not to have inhibitory synapses ${ }^{15,46}$. Inhibitory synapses on branches I and II were made identical, although those on section I may have a different control ${ }^{47}$.

Passive properties and ionic channels. The passive properties of the SC model include $\mathrm{R}_{\text {axial }}$ which was set to $110 \Omega \mathrm{cm}$ for all the compartments, $R_{\text {input }}=0.75 \pm 0.06 \mathrm{G} \Omega, C_{m}$ was set to $1.5 \mu \mathrm{F} / \mathrm{cm}^{2}$ for the dendrites while the rest of the compartments was set to $1 \mu \mathrm{F} / \mathrm{cm}^{2}$. The reversal potential $\left(\mathrm{E}_{\mathrm{rev}}\right)$ of each ionic species was defined as follows: $\mathrm{E}_{\mathrm{Na}}=60 \mathrm{mV}, \mathrm{E}_{\mathrm{k}}=-84 \mathrm{mV}, \mathrm{E}_{\mathrm{Ca}}=137.5 \mathrm{mV}, \mathrm{E}_{\mathrm{h}}=-34 \mathrm{mV}, \mathrm{E}_{\text {leak }}=-48 \mathrm{mV}$. The leakage $\mathrm{G}_{\mathrm{i}-\max }$ was set to $3 e-5 \mathrm{~S} / \mathrm{cm}^{2}$ for all the compartments. The SC ionic channel models and distributions were taken from previous papers and updated according to the latest literature when needed [see Supplemental Material for details; ${ }^{33}$ ]. 
A
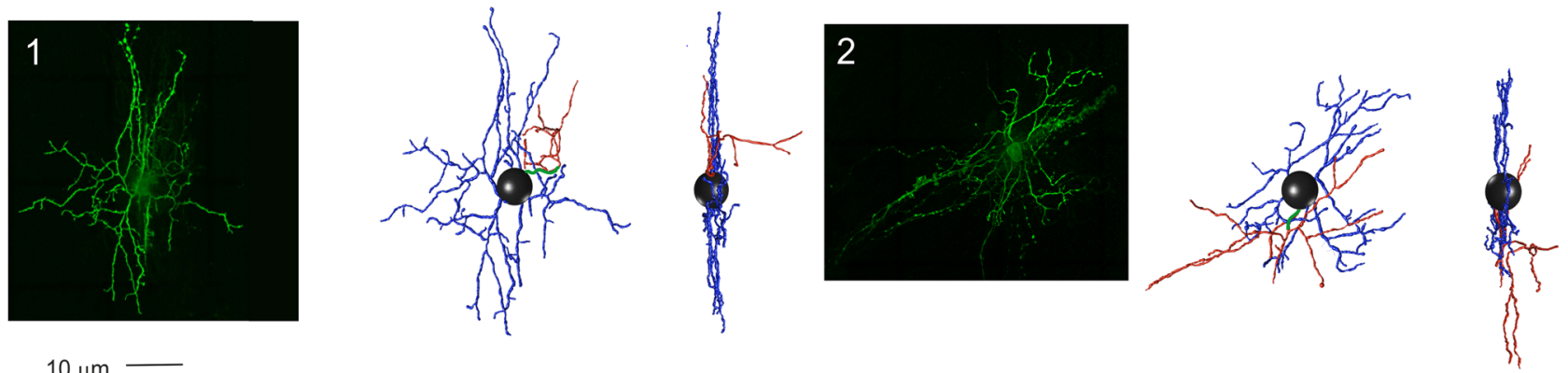

$10 \mu \mathrm{m}$
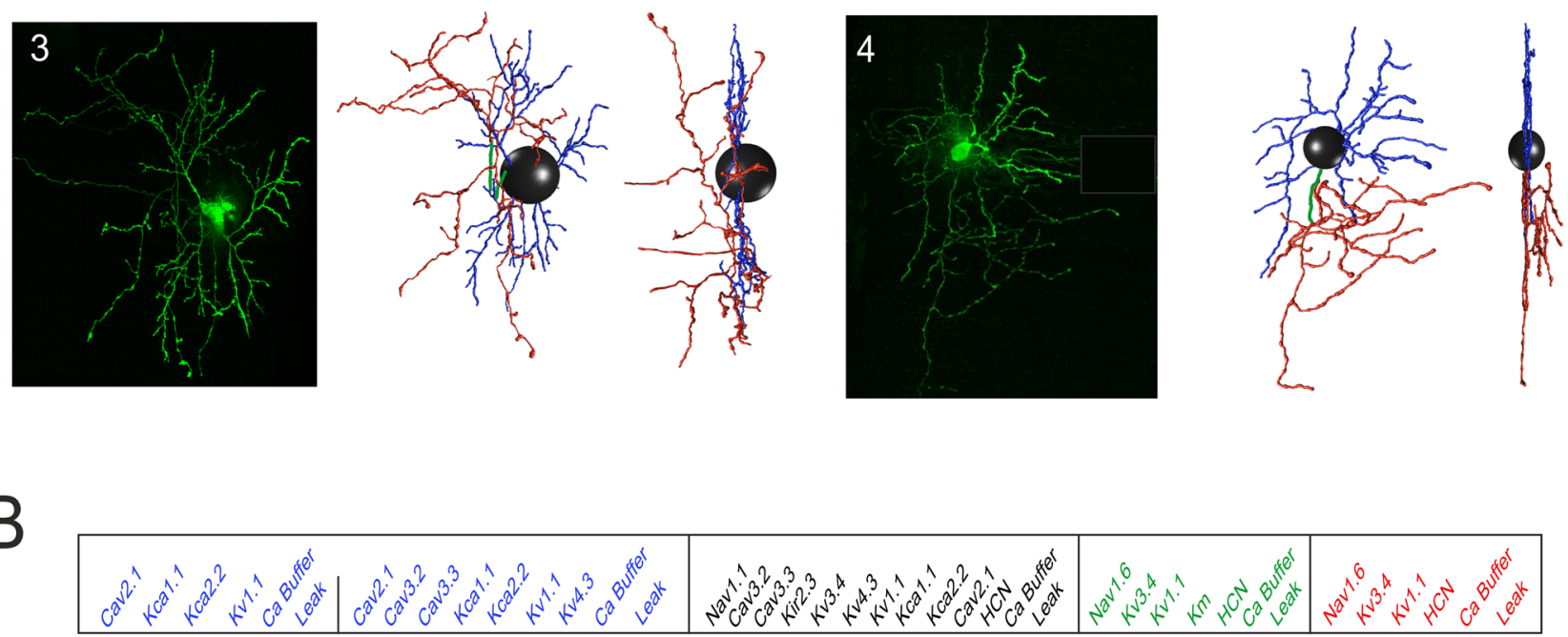

Distal Dendrites

$<0.6 \mu \mathrm{m}$

Proximal Dendrites
$>0.6 \mu \mathrm{m}$

Soma

AIS

Axon

Figure 1. Stellate cell morphological reconstruction. (A) Confocal microscopy imaging of four mouse SCs filled with Lucifer yellow (scale bar $10 \mu \mathrm{m}$ ) are shown along with the corresponding digital reconstruction with Neurolucida (visualization with Vaa3D simulator; right). The 3D morphological reconstructions of SCs include dendrites (blue), soma (black), AIS (green) and axon (red). (B) The SC model is divided into five electrotonic compartments and endowed with specific ionic mechanisms according to immunohistochemical data. The proximal and distal dendrites are distinguished at the cut-off diameter of $0.6 \mu \mathrm{m}$. Ionic channels include $\mathrm{Na}^{+}, \mathrm{K}^{+}$ and $\mathrm{Ca}^{2+}$ channels and a $\mathrm{Ca}^{2+}$ buffering system.

The model included $\mathrm{Na}^{+}$channels (Nav1.1 and Nav1.6), $\mathrm{K}^{+}$channels (Kv3.4, Kv4.3, Kv1.1, Kir2.3, Kv7, KCa1.1 and KCa2.2), $\mathrm{Ca}^{2+}$ channels (Cav2.1, Cav3.2 and Cav3.3), hyperpolarization-activated cyclic nucleotide-gated channels $(\mathrm{HCN} 1)$ and a parvalbumin-based $\mathrm{Ca}^{2+}$ buffer. It should be noted that most of ionic channel kinetics were measured from neurons other than SCs. This is a standard procedure since whole-cell voltage-clamp recordings are unpractical in most neurons with extended neurites, while high-quality ionic channel equations can be retrieved from reconstituted systems and are available from data-banks previous papers (for a discussion of the issue, $\sec ^{33-35}$ ).

Excitatory and inhibitory neurotransmission. SCs receive synaptic activity from excitatory pathways, such as the $\mathrm{GrC}$ axons and the diffusion from climbing fibers and local inhibitory pathways. The inhibitory activity of SC modules the spike transmission to PC. Several studies have proved the presence of specific types of AMPA and NMDA receptor-mediated currents in cerebellar $\mathrm{SC}^{44,48,49}$. AMPA and NMDA receptors, built with the Tsodyks formalism ${ }^{50}$, were used to simulate the excitatory synaptic activity from the PFs to SC dendrites.

The AMPA receptor received the following parameters ${ }^{44}$ : release probability $(p)=0.15$, recovery time constant $\left(\tau_{\mathrm{R}}\right)=35.1 \mathrm{~ms}$, facilitation time constant $\left(\tau_{\mathrm{F}}\right)=10.8 \mathrm{~ms}$, maximum ionic conductance $\left(\mathrm{G}_{\mathrm{i}-\max }\right)=2300 \mathrm{pS}$ per synapse, ionic reversal potential $\left(\mathrm{E}_{\text {rev }}\right)=0 \mathrm{mV}$ (Supplementary Fig. 3A and Table 3 ).

The NMDA kinetic scheme was adapted to simulate the presence of the NR2B subunit ${ }^{48}$. NMDA NR2B receptor was modeled following the kinetics of the work of ${ }^{51}$ and the fitted parameters were: $p=0.15, \tau_{R}=8 \mathrm{~ms}$, $\tau_{\mathrm{F}}=5 \mathrm{~ms}, \mathrm{G}_{\mathrm{i}-\max }=10,000 \mathrm{pS}$ per synapse, $\mathrm{E}_{\mathrm{rev}}=-3.7 \mathrm{mV}$ (Supplementary Fig. 3B and Table 3). 
The $\mathrm{GABA}_{\mathrm{A}}$ receptor model maintains the kinetic scheme described in the work of ${ }^{52}$ and modified by maintaining the $\alpha 1$ subunit but deleting the $\alpha 6$ subunit (absent in the MLI) as follows: $p=0.42, \tau_{\mathrm{R}}=38.7 \mathrm{~ms}, \tau_{\mathrm{F}}=0 \mathrm{~ms}$, $\mathrm{G}_{\mathrm{i}-\max }=1600 \mathrm{pS}$ per synapse, $\mathrm{E}_{\mathrm{rev}}=-65 \mathrm{mV}$ (Supplementary Fig. $3 \mathrm{C}$ and Table 3).

AMPA and NMDA receptors were placed on three distal dendrite compartments. $\mathrm{GABA}_{\mathrm{A}}$ receptors were activated randomly on the dendrite compartments.

Model EPSCs and IPSCs were adapted to reproduce unitary synaptic current from SCs ${ }^{23,44,52}$ (Supplementary Fig. 3). The glutamatergic AMPA and NMDA receptors synaptic $\mathrm{G}_{\mathrm{i}-\max }$ parameter was balanced to reproduce a single PF EPSC, while $p$ parameter was balanced to reproduce short-term facilitation and short-term depression (STF and STD) in SC EPSCs during a stimulus train.

Parameter optimization. In this work, we used an innovative technique that allows rapid and automatic parameter optimization, based on multi-objective evolutionary algorithms, called "Indicator-Based Evolutionary Algorithm" (IBEA) ${ }^{53}$, in the BluePyOpt Framework ${ }^{45}$, to estimate the maximum ionic conductance parameters $\left(\mathrm{G}_{\mathrm{i}-\mathrm{max}}\right)$ (the free parameters of the model) of all ionic channels distributed along the morphology sections obtaining models able to reproduce the SC electroresponsiveness elicited by somatic current injections ${ }^{40}$.

The optimization workflow followed the same procedure used for parameters tuning in $\mathrm{GrCs}^{34,35}$. A set of $36 \mathrm{G}_{\mathrm{i}-\max }$ values were tuned to match the firing patterns revealed by electrophysiological recordings. From the experimental traces, used as templates, we extracted the experimental features necessary to assess the fitness functions for the optimization procedure.

The following features, selected to better reproduce the biophysical properties of action potentials, were extracted using the 'Electrophys Feature Extraction Library' (eFEL) ${ }^{54}$ during the spontaneous firing and the current injection protocols: $\mathrm{AP}_{\mathrm{Ampl}}(\mathrm{mV}), \mathrm{AP}_{\mathrm{AHP}}(\mathrm{mV}), \mathrm{AP}_{\mathrm{Thr}}(\mathrm{mV}),\left(\mathrm{AP}_{\mathrm{HW}}\right)(\mathrm{ms}), \mathrm{AP}_{\text {Freq }}(\mathrm{Hz})($ Supplementary Tables 4 and 5).

Optimization tests were applied to have four different best models based on the four morphologies, starting the process with the same range of conductances. Tests were performed on Piz Daint Cluster (CSCS-Lugano), using two nodes for a total of 72 cores, with simulations of $2000 \mathrm{~ms}$, fixed steps of $0.025 \mathrm{~ms}$, temperature of $32^{\circ} \mathrm{C}$, as in the experimental recordings and all ionic current kinetics were normalized to this value using $\mathrm{Q}_{10}=3$ corrections ${ }^{55}$. The stimulation protocol included the spontaneous firing, two positive current injections $(4,16$ $\mathrm{pA})$ and a negative current injection ( $-16 \mathrm{pA}$ ) lasting for $2 \mathrm{~s}$. The optimizations involving 100 individuals for 50 generations, required $3 \mathrm{~h}$ of computation time.

It should be noted that, in principle, the spikes contain information relative to all the maximum ionic conductances of a neuron ${ }^{28,33}$. Indeed, model optimization using BluePyOpt ${ }^{45}$ was able to capture, starting from spike discharges elicited by somatic current injection, several unanticipated cellular properties including burst pause responses, either related to intrinsic excitability or to synaptic activation, that were further used for model validation.

Simulations and testing protocols. The best models yielded by the optimization process were simulated using protocols designed to reproduce the experimental ones. Each model was tested for: (i) the spontaneous firing frequency, (ii) the firing frequency obtained with positive current injections of $4 \mathrm{pA}$ and $16 \mathrm{pA}$, (iii) the AHP after current injection and (iv) the sag generated by $-16 \mathrm{pA}$ current injection. The models were further tested with synaptic protocols. (v) PF activation was tested with synaptic trains composed by 10 pulses @ $4 \mathrm{~Hz}, 10 \mathrm{~Hz}$, $20 \mathrm{~Hz}, 50 \mathrm{~Hz}, 100 \mathrm{~Hz}, 200 \mathrm{~Hz}, 500 \mathrm{~Hz}$. (vi) GABAergic inhibitory activity, between two pair of SC, was tested using a background stimulation at $20 \mathrm{~Hz}$ with either 20,27 or $32 \mathrm{GABA}_{\mathrm{A}}$ receptor-mediated synapses. The same $\mathrm{PF}$ trains were delivered in conjunction with the inhibitory background.

The SC model was also wired in a minimal microcircuit including PFs and a $\mathrm{PC}^{28}$. All the synapses involved were randomly distributed over the corresponding neuronal compartments. The PF formed 100 synapses on PC dendrites and 3 synapses on SC dendrites, the SCs formed 25, 50, 100, 200 or 300 synapses on PC dendrites. In a set of simulations, a second SC was connected through 32 synapses to the first one. SCs and the PC received PF stimuli made of 10 pulses @ $4 \mathrm{~Hz}, 10 \mathrm{~Hz}, 20 \mathrm{~Hz}, 50 \mathrm{~Hz}, 100 \mathrm{~Hz}, 200 \mathrm{~Hz}$ or $500 \mathrm{~Hz}$.

The simulations were performed on an AMD Threadripper 1950X (32 GB ram), with fixed time step of $0.025 \mathrm{~ms}$, temperature $32^{\circ}$. Simulation time was $2 \mathrm{~s}$ for spontaneous activity and current injections, $5 \mathrm{~s}$ to test PF-SC synaptic activity, $15 \mathrm{~s}$ to test the SC $->\mathrm{SC}->$ PC circuit.

Model validation. The model was validated at several levels by comparing its parameters to experimental measurements that were not used for construction. In particular, simulated spike amplitude and spike threshold (Fig. 2), spike delay, sag amplitude, and the first ISI (Fig. 3) and input-output gains during burst transmission (Fig. 6) were compared to experimental data without uncovering any statistically significant difference.

Data analysis. Custom Python-scripts (Python 2.7.15; https://www.python.org) were written to automatically analyze the set of Gi-max parameters at the end of each optimization, to run simulations and to extract features. The voltage and current traces were analyzed using MATLAB 2018a/b (MathWorks, Natick, MA, USA; https://www.mathworks.com), pClamp 10 software (Molecular Devices, CA, USA; https://www.moleculard evices.com), OriginPro8 (https://www.originlab.com) software and MS Excel 2007. All figures were created with CorelDraw Graphics Suite 2018 software (https://www.coreldraw.com). The morphologies were analyzed with NEURON 7.7 (https://neuron.yale.edu) and visualized with Vaa3D (https://alleninstitute.org). 


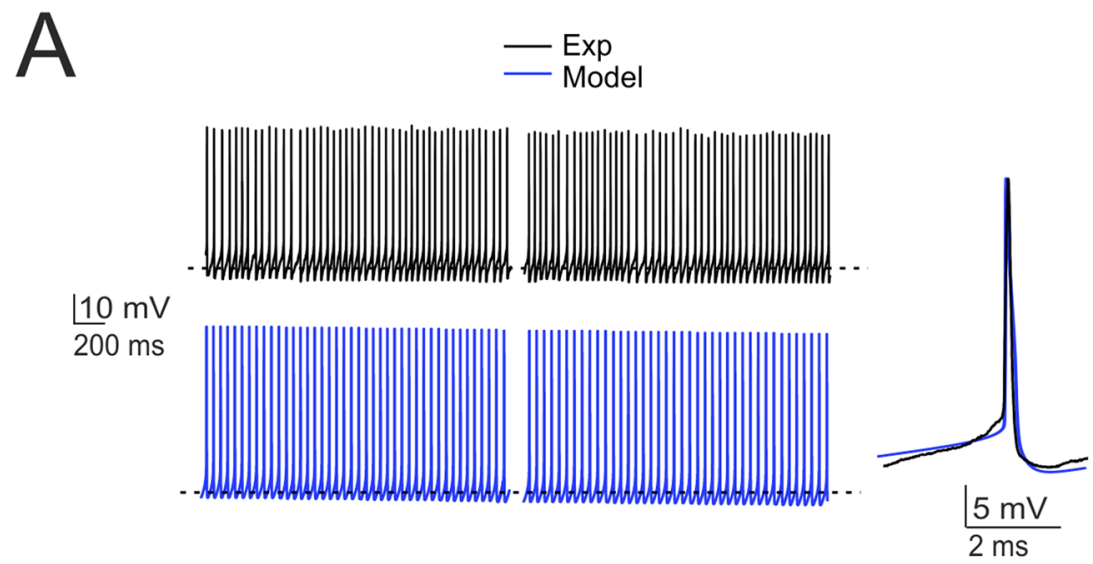

B

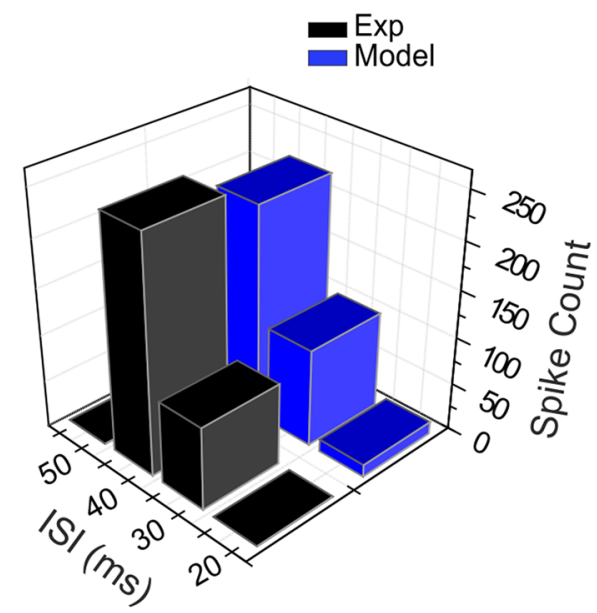

C

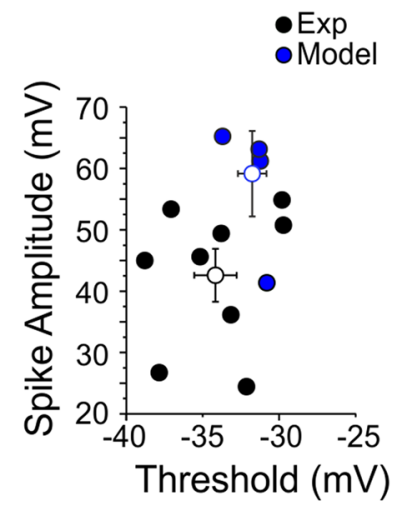

Figure 2. Pacemaking activity. (A) Pacemaker activity during SC WCR ( $\mathrm{n}=9$; black) and in the model $(\mathrm{n}=4$; blue) taken at different times (traces taken starting at $2 \mathrm{~s}$ and $6 \mathrm{~s}$ ). The inset shows a simulated and an experimental spike superimposed. (B) Distribution of the ISI of spontaneously firing SCs in WCR over $10 \mathrm{~s}$. Note that the ISI in the model (blue bar; $n=4$ ) falls within the experimental data distribution (black bar; $n=9$, $\mathrm{p}=0.8$ ). (C) Relationships among ISI parameters. Note that the model data points (blue circles; $\mathrm{n}=4$ ) fall within the distribution of spike amplitude vs. spike threshold measured experimentally (black circles; $n=9$ ). The model did not significantly differ from the experimental data $(p=0.64)$. Data are reported as mean \pm SEM.

\section{Results}

Stellate cell physiology and modeling. Detailed models of SCs of mouse cerebellum were generated starting from morphological reconstructions and using electrophysiological recordings as a template for the optimization of membrane mechanisms $s^{34,35}$ (full explanation is given in Supplemental Material). Morphologies of four SCs were reconstructed from immunofluorescent images taken from fixed preparations ex vivo. WCR from 23 SCs were obtained in acute cerebellar slices. All neurons were selected in the outer two thirds of the molecular layer, where SCs are the only neuronal species present ${ }^{6}$.

The four reconstructed SCs corresponded to the canonical description reported in literature $\mathrm{e}^{3,6,56}$. SCs showed a soma emitting 3-4 branched dendritic trees subdivided in proximal and distal sections, and axon initial segment (AIS) continuing in a branched axon (Fig. 1A). The soma surface measured $42.4 \pm 9.3 \mu \mathrm{m}^{2}(\mathrm{n}=4)$. Long, contorted and frequently branching dendrites extending from the soma were characterized centrifugally ${ }^{57,58}$, and quantified with two previously established measures ${ }^{59}$ : total dendritic length (the summed length of all dendritic segments; 845.2 $\pm 121.2 \mu \mathrm{m} ; \mathrm{n}=4$ ) and segment count (proximal dendrites: $11.0 \pm 3.0, \mathrm{n}=4$; distal dendrites: $63.5 \pm 14.0, \mathrm{n}=4$ ). Conversely, the axons branched immediately generating short and circumscribed collaterals (AIS length: $28.0 \pm 6.7 \mu \mathrm{m}, \mathrm{n}=4$; axon length: $577.9 \pm 225.0 \mu \mathrm{m}, \mathrm{n}=4$; Supplementary Table 2 and Movie 1). The dendritic tree was flattened on the sagittal plane of the folium and the axon, after an initial part parallel to the dendrite, advanced along the transverse plane ${ }^{6,11,20}$. The four morphologies were transformed into morpho-electrical equivalents (Fig. 1A) and used as the backbone for model reconstruction ${ }^{33}$. The SC models were divided into five electrotonic compartments and endowed with 14 different types of voltage-dependent and calcium-dependent ionic channels and with a calcium buffering system (Fig. 1B). 
A
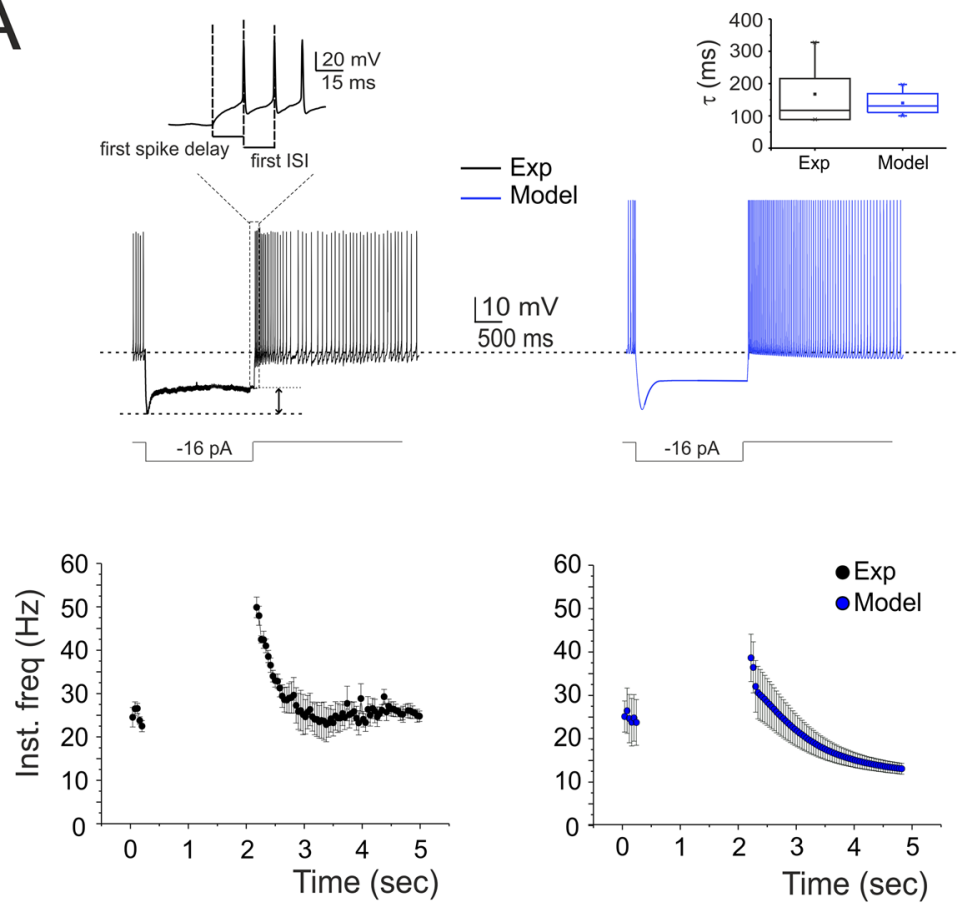

C
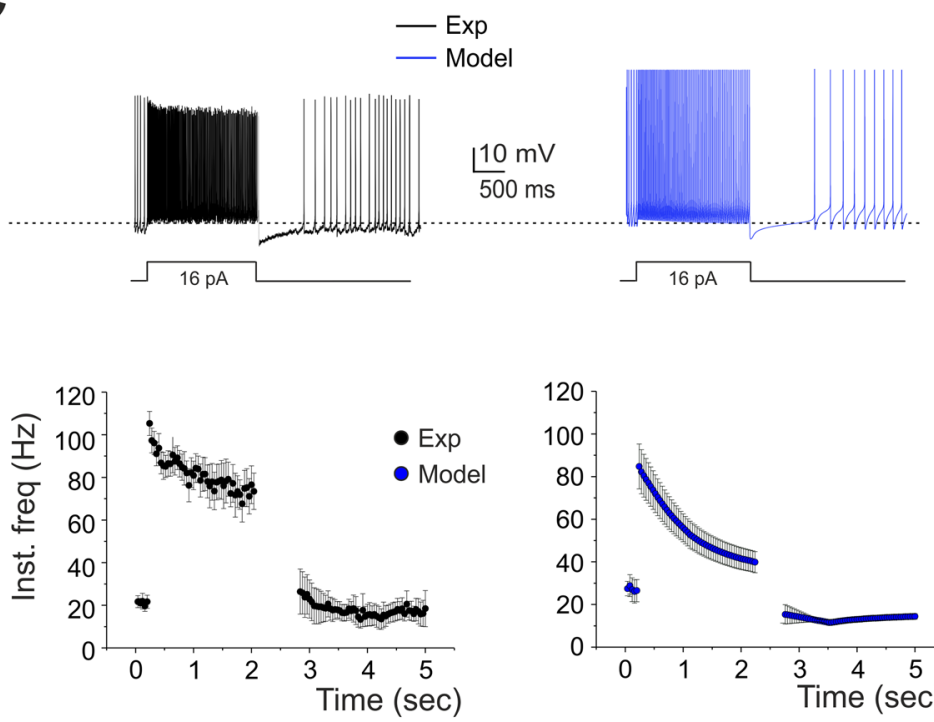

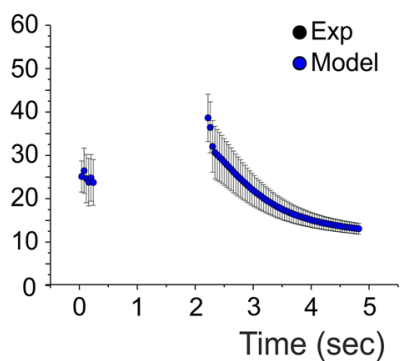

$16 \mathrm{pA}$

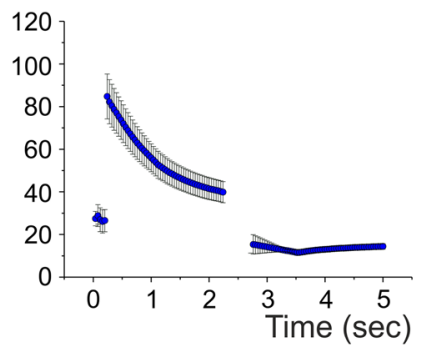

B
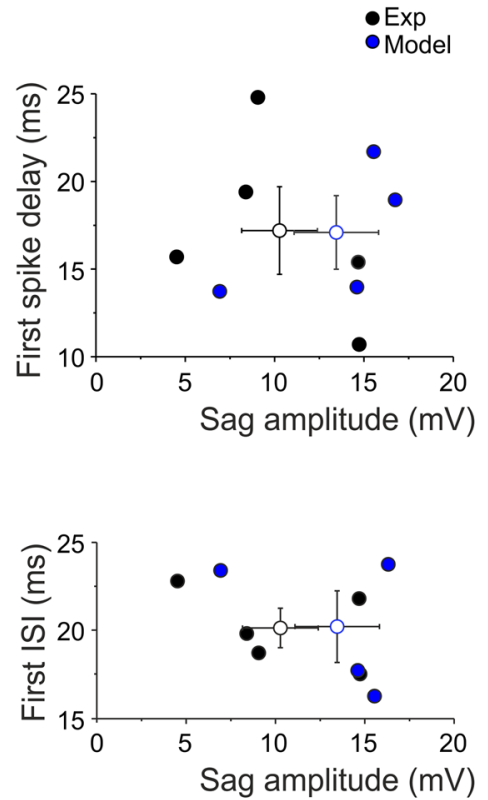

$D$
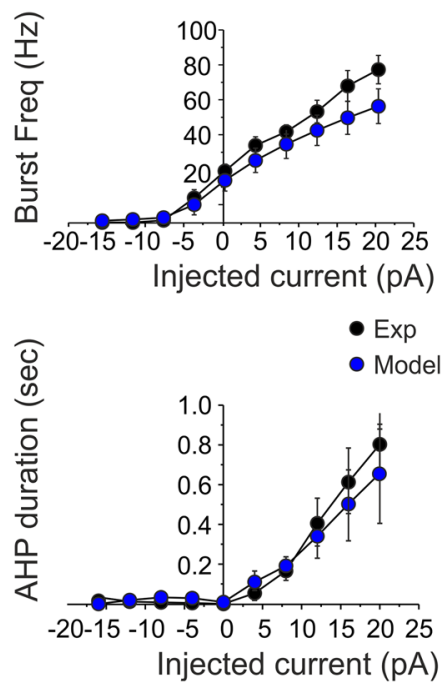

Figure 3. Response to hyperpolarization and depolarization. (A) A WCR from a SC shows sagging inward rectification in response to hyperpolarizing current injection and, at the end of the hyperpolarization, rebound excitation with an early and a protracted phase of intensified firing. Simulations of this specific experiment show that the model could faithfully reproduce sagging inward rectification and rebound excitation (blue trace). The enlarged trace on top shows how the first spike delay and the first ISI were determined. At the bottom, the time course of instantaneous spike frequency for a $-16 \mathrm{pA}$ current pulse. The box-and-whisker plot compares the sag decay time constant obtained in experiments $(n=6)$ and simulations $(n=4)$ without revealing statistically significant difference (unpaired $t$-test, $\mathrm{p}=0.4)(\mathrm{B})$ The plots report the time to first spike and the first ISI during rebound excitation as a function of sag amplitude (black circles; $\mathrm{n}=5$ ). Note that the model (blue circles; $\mathrm{n}=4$ ) did not significantly differ from the experimental data $(p=0.32)$. Data are reported as mean \pm SEM. (C) A WCR from a SC shows the firing frequency and the pause following depolarizing current step (16 pA). The time course of instantaneous spike frequency for the 16-pA current pulse is shown below. Simulations show that the model could faithfully reproduce this behavior (blue traces). (D) In the plots, the response of the model (blue circles; $\mathrm{n}=4$ ) to current injections (from -16 to $20 \mathrm{pA}$ ) is compared to experimental data (black circles; $\mathrm{n}=5$ ). Simulations show that the model could appropriately fit the experimental measurements of spike frequency versus injected current (16 pA: $p=0.097)$ and of pause versus injected current $(16 \mathrm{pA}: \mathrm{p}=0.69)$. Data are reported as mean \pm SEM. 
The electrophysiological properties of SCs were recorded from the cell somata of neurons located in the outer two thirds of the ML (Figs. 2, 3). The basic properties of SCs were homogeneous, according to anatomical indications $^{6}$; see also above), and could be summarized as follows. (i) SC input resistance was $1.3 \pm 0.1 \mathrm{G} \Omega ; n=23$ and membrane capacitance was $6.7 \pm 0.5 \mathrm{pF} ; \mathrm{n}=23$. (ii) the $\mathrm{SC}$ spike was narrow $\left(1.0 \pm 0.2 \mathrm{~ms}, \mathrm{n}=9\left(\mathrm{AP}_{\mathrm{HW}}\right)\right)$ and overshooting $\left(37.3 \pm 5.2 \mathrm{mV}\left(\mathrm{AP}_{\mathrm{Ampl}}\right)\right)$ (an example is shown in Fig. 2A and detailed parameters are reported in Supplementary Tables 4 and 5). (iii) SCs fired spontaneous action potentials at $16-36 \mathrm{~Hz}(24.2 \pm 2.1 \mathrm{~Hz} ; \mathrm{n}=9$; Fig. 2A). The average ISI distribution showed a single peak at $45.4 \pm 3.5 \mathrm{~ms}(\mathrm{n}=9$; Fig. 2B). There was no correlation between spike amplitude and threshold (Fig. 2C). (iv) When injected with hyperpolarizing current steps, SCs showed sagging inward rectification and, after hyperpolarization, showed rebound excitation (Fig. 3A). Rebound excitation consisted of accelerated spike frequency, which progressively decayed back to baseline. There was no correlation between the amplitude of the hyperpolarizing sag $(10.3 \pm 2.0 \mathrm{mV} ; \mathrm{n}=5)$, the first spike delay $(17.2 \pm 2.3 \mathrm{~ms} ; \mathrm{n}=5)$ or the first ISI $(20.1 \pm 1.0 \mathrm{~ms} ; \mathrm{n}=5)$ (Fig. 3B). (v) When injected with depolarizing current steps, SCs generated fast repetitive spike discharge. The output frequency increased almost linearly with current intensity (slope $2.79 \mathrm{~Hz} / \mathrm{pA} ; \mathrm{n}=5$ ) (Fig. 3C,D). (vi) At the end of spike discharges elicited by step current injections, SCs showed a marked AHP delaying the re-establishment of pacemaker activity. The AHP duration increased with stimulation intensity (Fig. 3D).

The models (see "Methods" and Supplemental Material) faithfully reproduced all the properties reported above, as shown in Figs. 2 and 3. The statistical comparisons reported below demonstrate the absence of significant differences between the data obtained in WCR and the SC models. In detail, the model (i) matched the passive neuron properties, (ii) reproduced spike shape (Supplementary Tables 4 and 5), (iii) showed an average pacemaker frequency within the experimental data distribution (Fig. 2A,B; Supplementary Movie 2), (iv) responded to negative current injections, reproducing sagging inward rectification and rebound excitation (Fig. 3A), (v) increased firing rate with an almost linear I/O relationship in response to step current injections (slope $2.13 \mathrm{~Hz} / \mathrm{pA} ; \mathrm{n}=4$ ) (Fig. 3D), (vi) showed a hyperpolarization followed by a pause in spike firing at the end of the current steps (Fig. 3D). The parameters of the four SC models corresponding to these electrophysiological properties fell within the experimental data distributions ( $\mathrm{p}>0.1$, unpaired $t$-test), indicating that SCs electrical responses recorded in experiments and models could be treated as members of the same statistical distribution. The electroresponsive mechanisms of the models are shown in Supplementary Figs. 1 and 2 and quantified in Supplementary Fig. 4, highlighting the specific involvement of $\left[\mathrm{Ca}^{2+}\right]_{i}$ changes, Cav3.2, KCa1.1 and other voltage-dependent ionic channels operating in SCs.

Frequency-dependent short-term dynamics at parallel fiber-stellate cell synapses. In order to understand how information transmitted by GrC inputs is encoded by SCs, we investigated response dynamics at PF-SC synapses activated by trains of $20 \mathrm{PF}$ stimuli at different frequencies (50, 100 and $200 \mathrm{~Hz}$ ), to preserve PFs, these experiments were performed in coronal slices (see "Methods"). During the stimulus trains, EPSCs showed an initial strong facilitation followed by depression, which however did not make the response smaller than control (Fig. 4A,B) ${ }^{60-62}$. The sequence of STF and STD was the more evident the higher the stimulation frequency, suggesting that frequency-dependent short-term synaptic dynamics could regulate transmission efficacy along the PF-SC pathway ${ }^{17}$.

The PF-SC model of synaptic transmission ${ }^{44,50}$ was tuned to follow the experimental results yielding release probability, $p=0.15^{44,48,49}$. The low $p$ level generated STF, while vesicle depletion during the train caused the subsequent STD (Fig. 5A). The model precisely followed the experimental results (cf. Figure 4B). The NMDA receptors enhanced PF-SC synaptic transmission (Fig. 5A inset; see also Fig. 7B).

For comparison, we have run a similar simulation on a PC model $^{28,33}$, resulting in a similar sequence of STF and STD but with different frequency-dependence (Fig. 5B). The different frequency dependence was related to the different release probability and the different time constants determining short-term plasticity dynamics (see Supplementary Table 3). This observation suggested that the two cells, if wired together, would generate specific filtering effects (see below). The gain curve with respect to input burst frequency showed a sigmoidal shape with $50 \%$ amplitude around $50 \mathrm{~Hz}$ for the SC and around $10 \mathrm{~Hz}$ for the PC (Fig. 5C).

Frequency-dependence of stellate cell input-output gain functions. The impact of short-term dynamics at PF-SC synapses was investigated by measuring the responses to PF bursts at different frequencies (10 pulses@ $4 \mathrm{~Hz}, 10 \mathrm{~Hz}, 20 \mathrm{~Hz}, 50 \mathrm{~Hz}, 100 \mathrm{~Hz}, 200 \mathrm{~Hz}, 500 \mathrm{~Hz}$ ). Pronounced spike bursts were generated at high frequencies (e.g. at $100 \mathrm{~Hz}$, the frequency increase was $154.5 \pm 40.5 \%, \mathrm{n}=4 ; \mathrm{p}=0.046$; Fig. $6 \mathrm{~A}$ ). A careful analysis of PSTHs showed a delay in the first spikes of SCs in response to high-frequency PF stimulation (about $50 \mathrm{~ms}$ at $100 \mathrm{~Hz}$ ) probably determined by STF in synaptic transmission (Fig. 6B). The analysis of responses to different PF input frequencies revealed that SC responses did not increase their spike output frequency above the basal frequency below about $10 \mathrm{~Hz}$, then their responses increased and tended to saturate beyond $100 \mathrm{~Hz}$ (Fig. 6C). The input/output gain curve showed a sigmoidal shape (Fig. 6D). This effect was related to STF, since it disappeared when STF was switched off (Fig. 6D).

The models were calibrated by activating an increasing number of synapses at $100 \mathrm{~Hz}$, reveling that an output frequency like the experimental one was obtained using just 3 PF-SC synapses (Fig. 6A, inset). The experimental data were then faithfully reproduced by the models (Fig. 6 A-D; see also Supplementary Fig. 3) by simply using the electroresponsiveness and synaptic transmission properties calibrated beforehand, thus providing a mechanistic explanation for the time-dependent and frequency-dependent properties of SCs synaptic responsiveness.

The model was further used to evaluate the effect of factors that could modulate the gain curve. NMDA current stimulation ${ }^{49,63}$; 64 blockage reduced (though not significantly) the SC firing rate during high-frequency bursts (e.g. at $200 \mathrm{~Hz}$, frequency change was $-21.4 \pm 9.2 \%, n=4 ; p=0.13$; Fig. $7 \mathrm{~A}, \mathrm{~B}$ ). Of special interest was the 
A
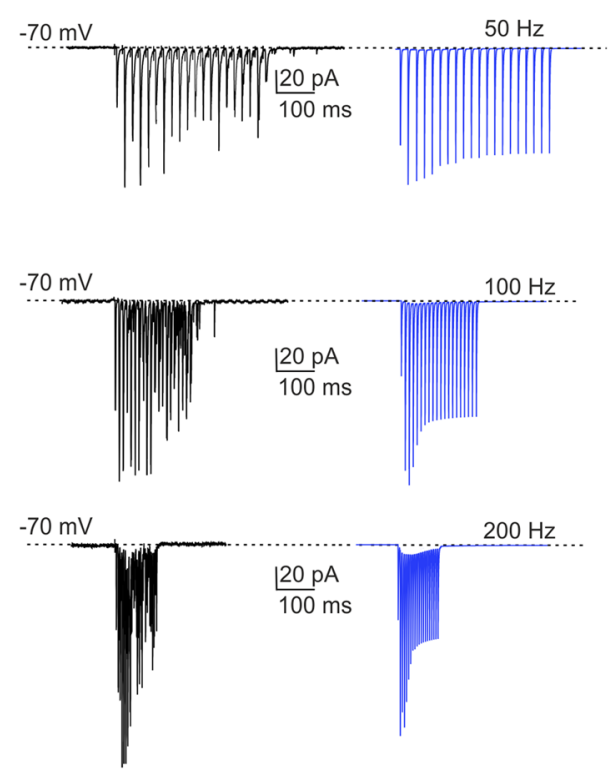

B
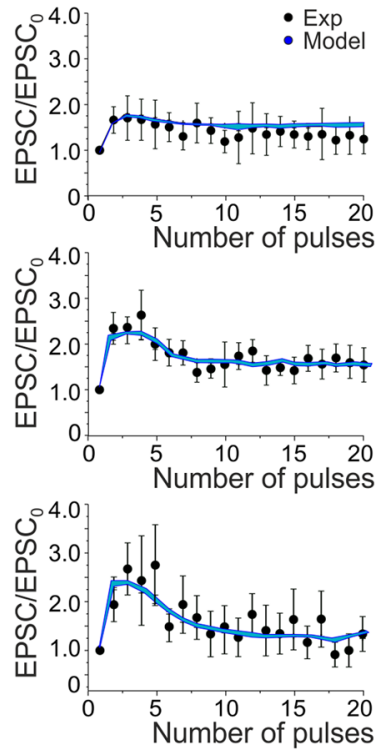

Figure 4. Short-term plasticity at PF-SC synapses. (A) EPSCs recorded from the SC during 50, 100 and $200 \mathrm{~Hz}$ parallel fiber stimulations $(n=6)$. Cells were voltage-clamped at $-70 \mathrm{mV}$ and in the presence of gabazine. Each trace (black) is an average of 10 sweeps. Note that EPSC trains showed first facilitation and then depression. Simulations show that the model could faithfully reproduce the same behavior (blue traces; $n=4$ ).

(B) Comparison of peak amplitudes of experimental and simulated EPSCs during high-frequency parallel fiber stimulation. Amplitudes are normalized to the first EPSC in the train (correlation coefficient $\mathrm{R}^{2} @ 50 \mathrm{~Hz}=0.80$; @ $100 \mathrm{~Hz}=0.90 ; @ 200 \mathrm{~Hz}=0.84)$. Data are reported as mean \pm SEM.

simulated effect of inhibitory $\mathrm{GABA}_{\mathrm{A}}$ receptor-mediated synaptic transmission from neighboring SCs ${ }^{42,52,65,66}$. To estimate the strength of this connectivity, a series of simulations were performed with different numbers of inhibitory synapses activated simultaneously with PF bursts. While increasing the inhibitory strength, SC excitation was moved toward higher frequencies and the activation curve became steeper $\left(50 \mathrm{~Hz}_{(\mathrm{mod})}:-70.9 \pm 9.4 \%, \mathrm{n}=4\right.$; $p=0.009$; Fig. 7B). Dendritic voltage-dependent currents activated during repetitive synaptic stimulation of the SC model are considered in Supplemental Material (Supplementary Fig. 5; compare the currents elicited by step current injection in Supplementary Fig. 4). In conclusion, during PF stimulation, NMDA receptor modulation was more evident at higher frequencies whereas GABAergic modulation was more evident at lower frequencies suggesting that two synaptic systems had opposite effects on the SC gain function.

Prediction of stellate cell filtering of Purkinje cell responses. SCs provide feed-forward inhibition to PCs ${ }^{14,15,28}$. Here, the different frequency-dependence of SC and PC responses to input bursts suggested that SCs could act as filters, when the two cells are co-activated (Fig. 8A).

To explore the issue, we performed simulations in which SCs were synaptically connected to PCs (Supplementary Movie 3, 4). When SC synapses were activated, the PC was inhibited and its output spike frequency decreased. The effect was stronger at high input frequencies, where SCs are more activated. Consequently, a sufficient number of SC synapses $(>=50 \mathrm{~Hz})$ abolished the response of PCs at high frequency $(>50 \mathrm{~Hz})$ without affecting that at low frequency $(<50 \mathrm{~Hz})$, de facto flattening the gain curve. In this configuration, the SC-PC system acted as an effective low-pass filter (Fig. 8B,C).

SCs are wired together through inhibitory synapses. We therefore performed simulations in which, in addition to stellate-PC feed-forward inhibition, SCs were reciprocally inhibited. In this case, the effect on the PC gain curve changed. Reciprocal inhibition reduced SC activity above $50 \mathrm{~Hz}$, while leaving the PC excited above $10 \mathrm{~Hz}$ (cf. Fig. 5C). In this configuration, the $\mathrm{SC}->\mathrm{SC}->\mathrm{PC}$ system acted as low-pass filter was partially deactivated (Fig. 8B,C).

PCs normally generate burst-pause responses following PF bursts ${ }^{28,67}$. The simulations showed that, along with the burst, the SCs also regulated the pause although in an opposite manner (Fig. 8B,C). The pause was almost insensitive to input frequency but increased remarkably along with SC inhibition. It should be noted that the pause persisted even when PF stimulations lasted hundreds of milliseconds, as it happens in certain behavioral tasks like eye-blink classical conditioning ${ }^{68}$ (Supplementary Fig. 5A). Finally, SCs activity delayed PC responses by about $20 \mathrm{~ms}$ (Fig. 8D). In aggregate, these simulations show that SCs exert a remarkable effect on the delay, band-pass and burst-pause behavior of PCs. 


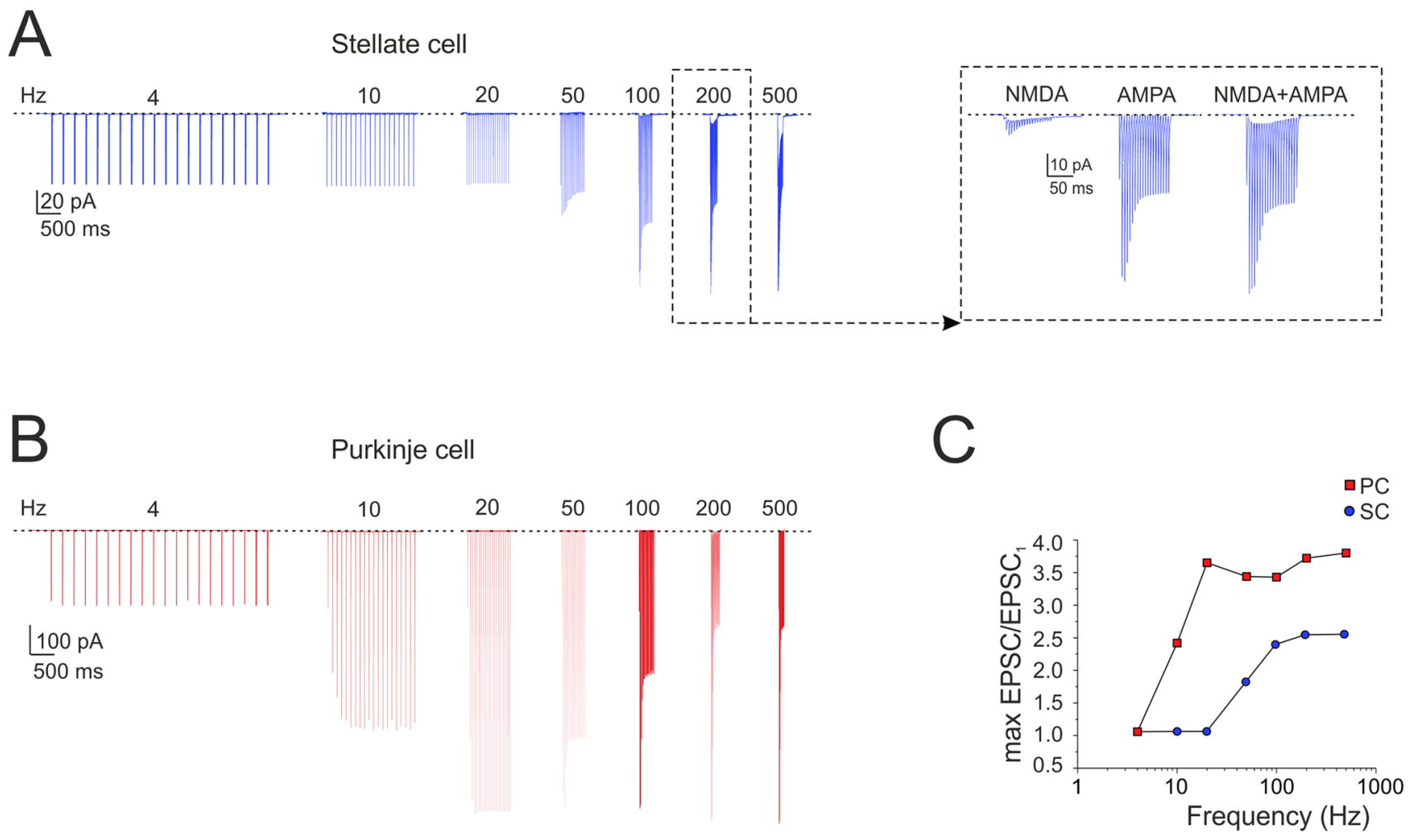

Figure 5. Burst currents at PF-SC and PF-PC cell synapses. (A) The traces show simulated SC EPSCs during trains of 20 stimuli delivered to PFs at different frequencies $(4,10,20,50,100,200$ and $500 \mathrm{~Hz} ; \mathrm{n}=4)$. Inset, NMDA, AMPA and NMDA + AMPA currents at $200 \mathrm{~Hz}$. (B) The traces show simulated PC EPSCs during trains of 20 stimuli delivered to PFs at different frequencies (4, 10, 20, 50, 100, 200 and $500 \mathrm{~Hz}$ ). (C) Gain curve for SC (blue circles; $n=4$ for each frequency) and PC (red squares) responses with respect to input burst frequency. Gain is the ratio between the maximum response obtained at a certain frequency and the first EPSC. The gain curves show a sigmoidal shape with $50 \%$ amplitude around $50 \mathrm{~Hz}$ for the $\mathrm{SC}$ and around $10 \mathrm{~Hz}$ for the PC. Data in $\mathrm{C}$ corresponds to the cells in $\mathrm{A}$ and $\mathrm{B}$.

\section{Discussion}

This work provides the first detailed models of a small set of cerebellar SCs. The models are based on precise morphological and electrophysiological measurements and faithfully reproduce the non-linear excitable properties and short-term neurotransmission dynamics at the PF-SC synapse. The models give insight into the critical role that these neurons could play in molecular layer processing. By exploiting membrane excitability and shortterm synaptic plasticity, SCs recode PF bursts and regulate the gain of PCs in a frequency-dependent manner. SC inhibition of PCs occurs above $10 \mathrm{~Hz}$ and, depending on the engagement of SC-SC inhibitory chains, can generate low-pass or band pass filters. These observations expand the concept of the cerebellum as an adaptive filter ${ }^{41}$.

Stellate cell electroresponsiveness and synaptic regulation. SCs showed autorhythmic firing around $25 \mathrm{~Hz}^{8,24}$. In slice preparations, PFs and climbing fibers are inactive ${ }^{69}$, and the only connection conveying spontaneous activity comes from other SCs and basket cells. It is thus probable that SC pacing reflected intrinsic electroresponsive properties since, in our recordings, GABAergic inputs were blocked pharmacologically. When stimulated with positive or negative currents, SCs showed burst-pause or pause-burst responses resembling those of other cerebellar neurons, comprising PCs ${ }^{28,38}$, Golgi cells ${ }^{31,32,70}$ and deep nuclear cells ${ }^{71,72}$. Therefore, SCs are well suited to take part into the complex bursting and pausing dynamics of the cerebellar circuit ${ }^{67}$.

While several ionic channels have been reported in these neurons, a couple of them revealed their fundamental role in burst-pause dynamics of SCs (see Supplementary Figs, 1, 2 and 4). HVA-type channels (Cav2.1) were critical to regulate $\left[\mathrm{Ca}^{2+}\right]_{\mathrm{i}}$ and $\mathrm{KCa} 1.1$, thereby determining adaptation and pauses after bursts. LVA-type channels (mostly Cav3.2) allowed to generate rebound bursting after a prolonged hyperpolarization. H-type channels (HCN1) activated during hyperpolarization and could regulate pause duration, while A-type channels (Kv4.3) were most active during rebound bursts and could regulate spike delay. The same ionic channels were activated during patterns of repetitive synaptic transmission composed of excitatory and inhibitory bursts (see Supplementary Fig. 5).

Synaptic currents reflected the specific receptor-channel properties reported in voltage-clamp recordings ${ }^{44,49,51,52}$ and, when coupled to a presynaptic release mechanism, faithfully accounted for repetitive neurotransmission in bursts at different frequencies. While AMPA receptor-mediated currents generated rapid EPSCs and fast membrane depolarization, NMDA currents caused a slower build-up of the response during the 
A

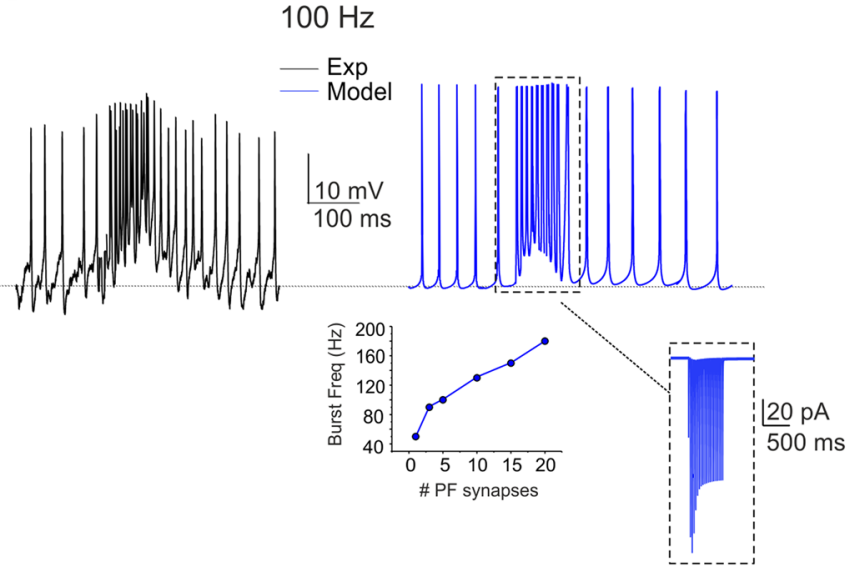

C

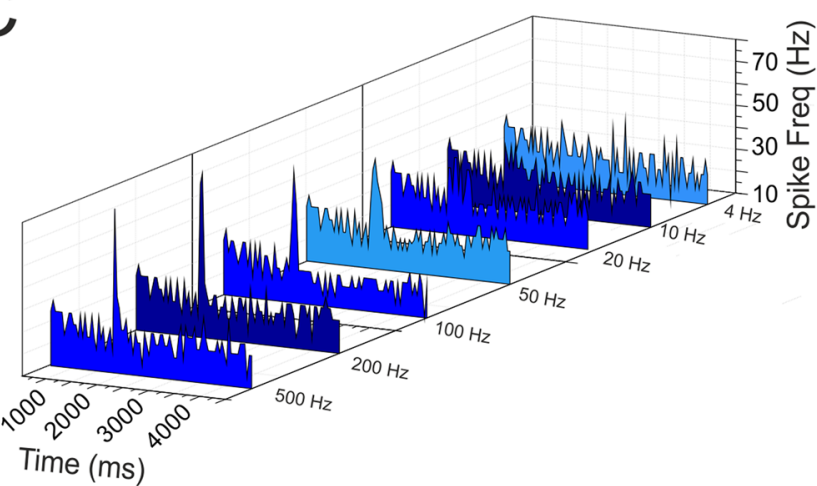

$100 \mathrm{~Hz}$

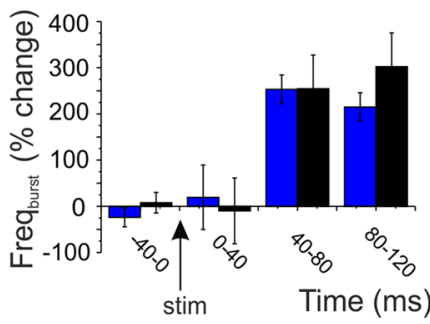

D

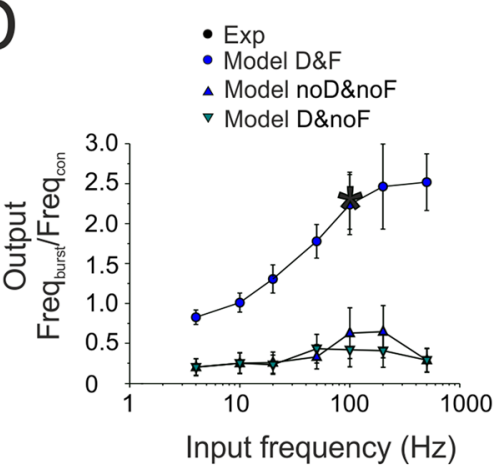

Figure 6. Frequency-dependence of SC input-output gain function. (A) The traces show a SC burst in response to 10 pulses @ $100 \mathrm{~Hz}$-delivered to PFs (black trace) and the corresponding simulation (blue trace). Inset (left), calibration of the number of PF-SC synapses required to obtain a given burst frequency ( 3 in the example). Inset (right), the synaptic current (AMPA + NMDA) corresponding to the simulated burst. (B) The histogram shows the time course of the SC burst shown in A in response to 10 pulses @ $100 \mathrm{~Hz}$-delivered to PFs (black trace) and the corresponding simulation (blue trace). Note the about $50 \mathrm{~ms}$ delay to burst response. (C) The array of PSTHs shows the SC responses to PF bursts at different frequencies (10 pulses @ $4 \mathrm{~Hz}, 10 \mathrm{~Hz}, 20 \mathrm{~Hz}$, $50 \mathrm{~Hz}, 100 \mathrm{~Hz}, 200 \mathrm{~Hz}, 500 \mathrm{~Hz}$ ). Note that pronounced spike bursts were generated at high frequencies (e.g. at $100 \mathrm{~Hz}$ ). (D) Input/output SC gain for experimental (black, $n=5$ ) and simulated bursts (blue, $n=4$ ). SCs did not increase their spike output frequency until about $10 \mathrm{~Hz}$, then their responses increased and tended to saturate beyond $100 \mathrm{~Hz}$. Note the superposition of the single experimental data point and simulated data (asterisk). The simulation was repeated after the switch-off of STF $\left(\tau_{\text {facil }}=10\right.$ times the original) and STD $\left(\tau_{\text {rec }}=0\right)$, revealing their critical role for the frequency-dependence of the input-output function. Data in B and D are reported as mean $\pm \operatorname{SEM}(\mathrm{n}=4)$.

trains. $\mathrm{GABA}_{\mathrm{A}}$ receptors generated $\mathrm{SC}$ inhibitory currents. Interestingly, the kinetics of synaptic response trains showed strong facilitation (STD followed the first impulses at $>50 \mathrm{~Hz}$ ) that, in the model, implied a low neurotransmitter release probability $(p=0.15)$. Consequently, the SCs generated spikes with a delay (about $50 \mathrm{~ms}$ during a $100 \mathrm{~Hz}$ train) and prevented responses to single PF spikes. This mechanism therefore effectively controls the timing of SC responses to bursts at the same time preventing their activation by single sparse PF spikes, which are therefore filtered out as noise.

As long as the models predict that SCs operate as delay-high-pass filters, they also anticipate the underlying mechanisms. The SC gain curves were enhanced by NMDA and reduced by $\mathrm{GABA}_{\mathrm{A}}$ receptor-mediated transmission, this latter also shifting the cut-off frequency from $\sim 50 \mathrm{~Hz}$ to $\sim 100 \mathrm{~Hz}$. The frequency-dependent effect reflected the short-term synaptic dynamics typical of these neurons and were enhanced by activation of NMDA currents and voltage-dependent ionic currents (mostly the LVA calcium current). GABA $\mathrm{A}_{\mathrm{A}}$ currents reduced the cell input resistance and prevented regenerative depolarizing effects (see also Supplemental Material).

Stellate cell regulation of Purkinje cell gain. The electrophysiological and imaging analysis of signal propagation and neuronal excitation ${ }^{17-19,63}$ has revealed that granular layer signals are retransmitted to PCs vertically at high frequency along $\mathrm{GrC}$ ascending axons and then transversally at low frequency along $\mathrm{PFs}^{73}$. The present simulations indeed provide a plausible mechanism for this dual nature of transmission properties through the granular and molecular layer. This view substantially differs from the classical "beam theory" 4,74 , 


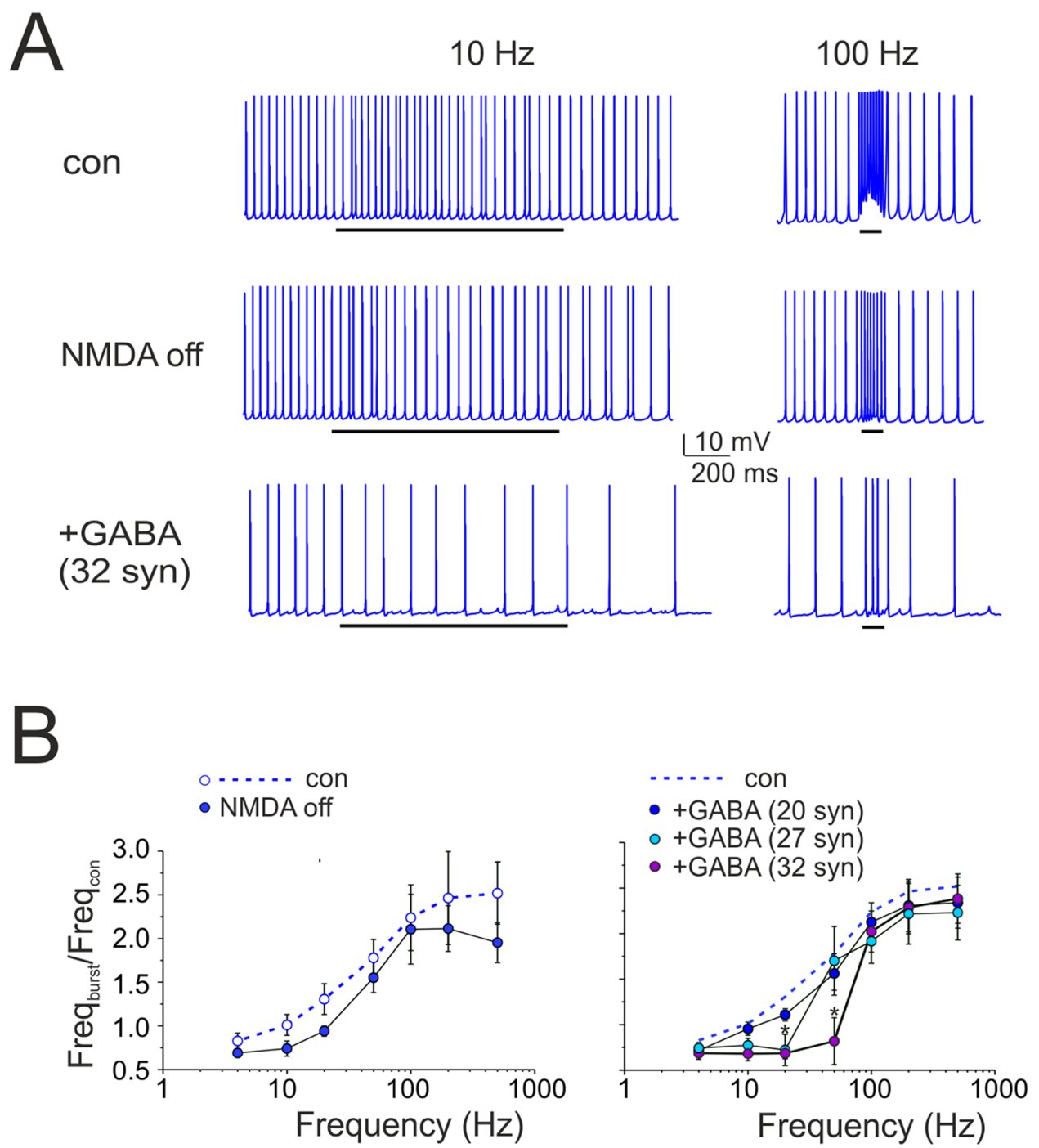

Figure 7. Regulation of SC gain function by NMDA and $\mathrm{GABA}_{\mathrm{A}}$ receptors. (A) The traces show simulated SC response to 10 pulses @ $100 \mathrm{~Hz}$-delivered to PFs. NMDA receptor switch-off and activation of inhibitory (32) synapses activated simultaneously with the PF burst reduced SC firing rate. Black bar indicates the stimulus duration. (B) Input/output SC gain regulation. Note that the NMDA current block reduced the spike output frequency mostly during high-frequency bursts $(200-500 \mathrm{~Hz})$, while a sufficient number of inhibitory synapses (activated simultaneously with PF bursts) shifted SC excitation toward higher input frequencies. Data are reported as mean $\pm \operatorname{SEM}(\mathrm{n}=4)$.

which maintained a central role for beams of PCs formed along the PFs. We cannot predict whether these PC beams will form or not, but we can anticipate that the PCs lying along the PFs receive a low-pass filtered signal from the PF- SC subcircuit that seems more suitable to synchronize them on the theta band than to perform actual information transfer from granular to molecular layer.

As well as SCs, also PCs showed STF and their gain increased with input frequency (cut-off $\sim 20 \mathrm{~Hz}$ ). When the SC and PC models were put in series along the PF beam so as to emulate a feed-forward inhibitory circuit ${ }^{14,15,28}$, the gain of PCs was limited to the values typical of low-frequency transmission $(4-10 \mathrm{~Hz})$ generating a low-pass filter. When the SC-SC feed-forward inhibition ${ }^{10,11}$ was activated, the gain curve of the PC showed a decrease beyond $100 \mathrm{~Hz}$, generating a band-pass filter.

Validation of these simulations is provided by experiments that were performed using voltage-sensitive dyes in coronal slices. While PCs on-beam showed increased gain at high frequency when $\mathrm{GABA}_{\mathrm{A}}$ receptors were blocked, their responses were low-pass filtered to the $4-10 \mathrm{~Hz}$ range when synaptic inhibition was active ${ }^{17}$. In addition to this, spots of PCs receiving activation along vertical beams, proved capable of high-frequency gain probably reflecting the exceeding number of $\mathrm{GrC}$ ascending axon synapses on PCs compared to the low number of PF synapses on local SCs ${ }^{15,18}$. Thus, while evidence for low-pass filtering is available, that for band-pass filtering awaits experimental validation. 
A
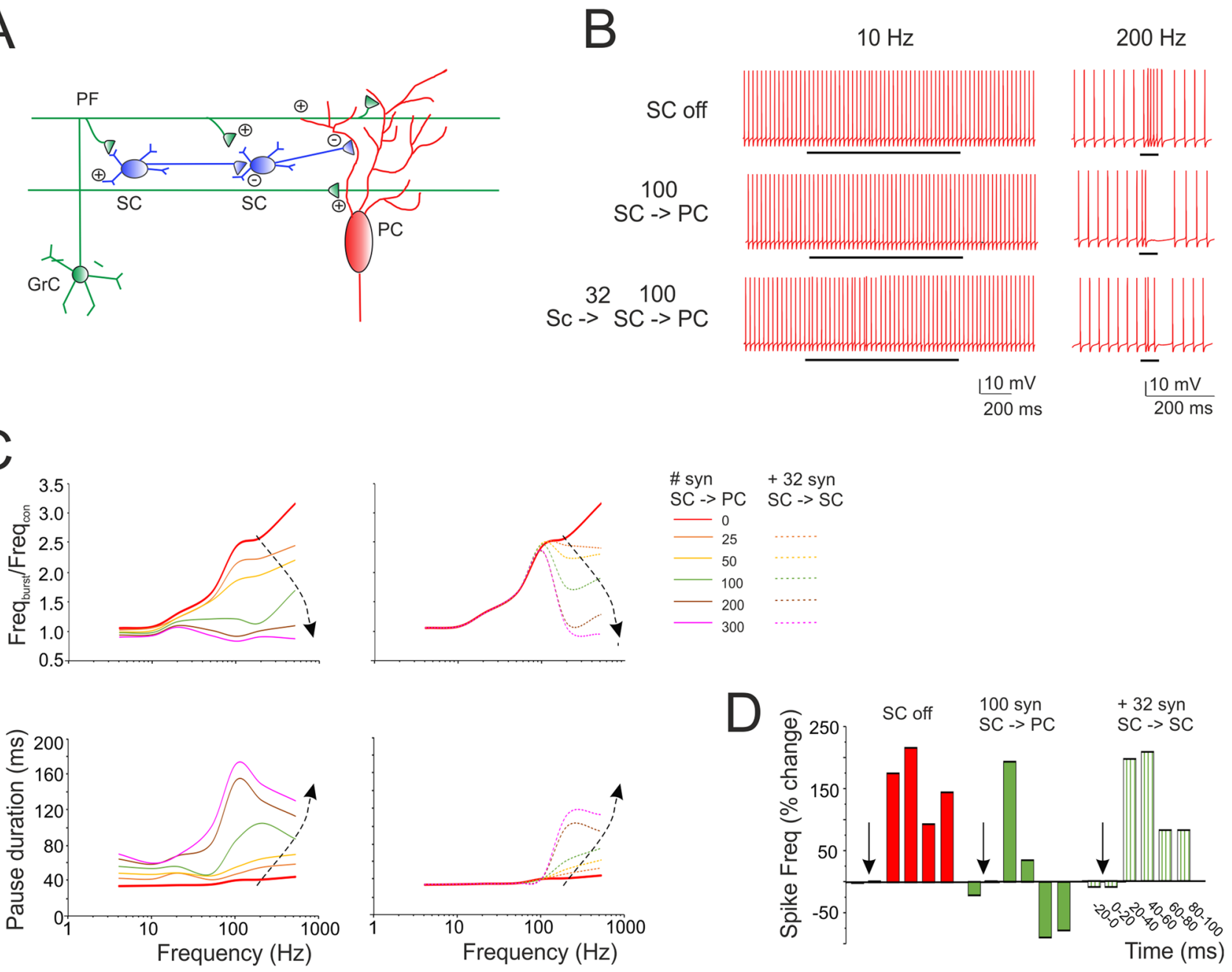

Figure 8. Prediction of SC filtering of PC responses along the PFs. (A) Schematics of the afferent connections to a PC activated by PF stimulation. Granule cell (GrC); parallel fiber (PF); stellate cell (SC); Purkinje cell (PC). The figure highlights the interactions of elements in the cerebellar molecular layer and the location of afferent PC synapses. (B) The traces show simulated PC response to 10 pulses at different frequencies (10, 200 and $500 \mathrm{~Hz}$ ) delivered to $100 \mathrm{PFs}$ in which (i) SCs were not activated (SC off), (ii) 100 SC synapses were activated (SC - > PC) and (iii) 100 SC synapses received inhibition from 32 SC synapses (SC - > SC - > PC). Black bar indicates the stimulus duration. (C) Input/output PC burst frequency gain (top) and pause length (bottom). Different curves are obtained using PF trains at different frequency $(10$ pulses@ $4 \mathrm{~Hz}, 10 \mathrm{~Hz}, 20 \mathrm{~Hz}, 50 \mathrm{~Hz}$, $100 \mathrm{~Hz}, 200 \mathrm{~Hz}, 500 \mathrm{~Hz}$ ) and an increasing number of inhibitory synapses. Dotted traces also include the case of SC-SC inhibition. Note that PC burst and pause showed an almost opposite modulation by SCs. (D) The histogram shows the regulation of PC firing frequency when SCs are off, on and reciprocally inhibited. Note that reciprocal SC inhibition can abolish the effect of SCs on PCs.

An interesting observation emerging from these simulations is the relatively high number of SC synapses required to inhibit PCs, which exceeds that anticipated by the SC/PC ratio obtained from morphological measurements ${ }^{75}$. Indeed, with 100 synapses we appropriately reproduced low-pass filtering ${ }^{17}$ and controlled PC firing as in the original observation of Eccles ${ }^{4}$. Importantly, the physiological effect of inhibition was analyzed in single cell models ${ }^{28,76}$ that already suggested that hundreds of SC synapses were required to effectively regulate PC discharge ${ }^{77}$. In aggregate, our simulations suggest that the number of inhibitory SC-PC synapses is higher than previously thought, opening an interesting question for future anatomo-physiological studies.

The molecular layer as an adaptive filter. A main prediction of the present simulations is that the intensity and bandwidth of molecular layer filtering is modulated by the number of active synapses between PFs, SCs and PCs. The number of active synapses, in turn, would depend on the organization of spike discharge in the PFs, and therefore, ultimately, on the reaction of the granular layer to the mossy fibers input ${ }^{78-80}$. Moreover, in addition to PF-PC synapses ${ }^{81-85}$, also the synapses between PFs and SCs ${ }^{86-88}$ and between SCs and PCs ${ }^{89-91}$ have been reported to develop long-term synaptic plasticity [for a recent review see ${ }^{92-94}$. It is therefore possible that the PF-SC-PC system operates as a bank of filters, in which gain and bandwidth of PC responses are finetuned by SCs. Interestingly, mechanisms of signal filtering tuned by local synaptic plasticity have recently been 
recognized also in the cerebellum granular layer ${ }^{35,95}$ extending the mechanisms that could actually transform the cerebellum into an adaptive filter ${ }^{41}$.

\section{Conclusions}

In conclusion, SCs emerge as critical elements controlling cerebellar processing in the time and frequency domain. In combination with VSD recordings ${ }^{17}$, the present simulations support the view that computation along PFs is different from that occurring in the spots of PCs laying vertically on top of active granular layer clusters $^{63,96,97}$. Tuning of transmission bandwidth and delay through specific membrane and synaptic mechanisms may contribute to explain the role of SCs in motor learning and control ${ }^{16}$. For example, transmission of low-frequency bursts along the PFs may help tuning the molecular layer with cortical low-frequency oscillatory inputs on the theta-band ${ }^{98,99}$, with reflections on circuit synchronization and on the induction of long-term synaptic plasticity. These potential consequences remain to be investigated using advanced recording techniques and large-scale circuit simulations ${ }^{39,100}$.

\section{Data availability}

The experimental traces can be found on the HBP knowledge Graph at this link: https://kg.ebrains.eu/searc h/instances/Dataset/3ca4af33-64bd-437a-9c53-2dac19e10168. The models will be made available on the Brain Simulation Platform (BSP) of the Human Brain Project (HBP) as a "live paper" containing a selection of routines and optimization scripts. A wider selection will be made available on the HBP knowledge Graph. The models will also be uploaded on ModelDB.

Received: 10 September 2020; Accepted: 17 December 2020

Published online: 16 February 2021

\section{References}

1. Golgi, C. in Archivio Italiano per le Malattie Nervose e più particolarmente per le Alienazioni Mentali Vol. 11 90-107 (1874).

2. Cajal, S. The Croonian Lecture. La fine structure des centres nerveux. Proc. R. Soc. Lond. 55, 444-468 (1894).

3. Cajal, S. Sobre las fibras nerviosas de la capa molecular del cerebelo. Rev. Trim. Histol. Norm. Patol. 1, 33-49 (1888).

4. Eccles, J., Ito, M. \& Szentagothai, J. The Cerebellum as a Neuronal Machine | SpringerLink, https://doi.org/10.1007/978-3-66213147-3 (1967).

5. Eccles, J. C. Circuits in the cerebellar control of movement. Proc. Natl. Acad. Sci. U S A 58, 336-343 (1967).

6. Chan-Palay, V. \& Palay, S. L. The stellate cells of the rat's cerebellar cortex. Z. Anat. Entwicklungsgesch. 136, 224-248 (1972)

7. Palay, S. \& Chan-Palay, V. Cerebellar Cortex: Cytology and Organization. (1974).

8. Hausser, M. \& Clark, B. A. Tonic synaptic inhibition modulates neuronal output pattern and spatiotemporal synaptic integration. Neuron 19, 665-678 (1997).

9. Jaeger, D. \& Bower, J. M. Synaptic control of spiking in cerebellar Purkinje cells: Dynamic current clamp based on model conductances. J. Neurosci. 19, 6090-6101 (1999).

10. Mittmann, W., Koch, U. \& Hausser, M. Feed-forward inhibition shapes the spike output of cerebellar Purkinje cells. J. Physiol. 563, 369-378. https://doi.org/10.1113/jphysiol.2004.075028 (2005).

11. Rieubland, S., Roth, A. \& Hausser, M. Structured connectivity in cerebellar inhibitory networks. Neuron 81, 913-929. https:// doi.org/10.1016/j.neuron.2013.12.029 (2014).

12. Wulff, P. et al. Synaptic inhibition of Purkinje cells mediates consolidation of vestibulo-cerebellar motor learning. Nat. Neurosci. 12, 1042-1049. https://doi.org/10.1038/nn.2348 (2009).

13. Jaeger, D., De Schutter, E. \& Bower, J. M. The role of synaptic and voltage-gated currents in the control of Purkinje cell spiking: A modeling study. J Neurosci 17, 91-106 (1997).

14. Santamaria, F., Tripp, P. G. \& Bower, J. M. Feedforward inhibition controls the spread of granule cell-induced Purkinje cell activity in the cerebellar cortex. J. Neurophysiol. 97, 248-263. https://doi.org/10.1152/jn.01098.2005 (2007).

15. Bower, J. M. Model-founded explorations of the roles of molecular layer inhibition in regulating Purkinje cell responses in cerebellar cortex: more trouble for the beam hypothesis. Front. Cell Neurosci. 4, https://doi.org/10.3389/fncel.2010.00027 (2010).

16. Jorntell, H., Bengtsson, F., Schonewille, M. \& De Zeeuw, C. I. Cerebellar molecular layer interneurons-Computational properties and roles in learning. Trends Neurosci. 33, 524-532. https://doi.org/10.1016/j.tins.2010.08.004 (2010).

17. Mapelli, J., Gandolfi, D. \& D’Angelo, E. High-pass filtering and dynamic gain regulation enhance vertical bursts transmission along the mossy fiber pathway of cerebellum. Front. Cell Neurosci. 4, 14. https://doi.org/10.3389/fncel.2010.00014 (2010).

18. Cohen, D. \& Yarom, Y. Cerebellar on-beam and lateral inhibition: Two functionally distinct circuits. J. Neurophysiol. 83, https ://doi.org/10.1152/jn.2000.83.4.1932 (2000).

19. Cohen, D. \& Yarom, Y. Patches of synchronized activity in the cerebellar cortex evoked by mossy-fiber stimulation: questioning the role of parallel fibers. Proc. Natl. Acad. Sci. U S A 95, 15032-15036 (1998).

20. Prestori, F., Mapelli, L. \& D’Angelo, E. Diverse neuron properties and complex network dynamics in the cerebellar cortical inhibitory circuit. Front. Mol. Neurosci. 12, https://doi.org/10.3389/fnmol.2019.00267 (2019).

21. ten Brinke, M. et al. Evolving models of Pavlovian conditioning: Cerebellar cortical dynamics in awake behaving mice. Cell Rep. 13, https://doi.org/10.1016/j.celrep.2015.10.057 (2015).

22. ten Brinke, M. et al. Cell Rep. 13, 1977-1988 (2015).

23. Llano, I. \& Gerschenfeld, H. Inhibitory synaptic currents in stellate cells of rat cerebellar slices. J. Physiol. 468, https://doi. org/10.1113/jphysiol.1993.sp019766 (1993).

24. Carter, A. G. \& Regehr, W. G. Quantal events shape cerebellar interneuron firing. Nat. Neurosci. 5, 1309-1318. https://doi. org/10.1038/nn970 (2002).

25. Molineux, M. L., Fernandez, F. R., Mehaffey, W. H. \& Turner, R. W. A-type and T-type currents interact to produce a novel spike latency-voltage relationship in cerebellar stellate cells. J. Neurosci. 25, 10863-10873. https://doi.org/10.1523/jneurosci.343605.2005 (2005).

26. Anderson, D. et al. The Cav3-Kv4 complex acts as a calcium sensor to maintain inhibitory charge transfer during extracellular calcium fluctuations. J. Neurosci. 33, 7811-7824. https://doi.org/10.1523/jneurosci.5384-12.2013 (2013).

27. Astori, S. \& Köhr, G. Sustained granule cell activity disinhibits juvenile mouse cerebellar stellate cells through presynaptic mechanisms. J. Physiol. 586, https://doi.org/10.1113/jphysiol.2007.146522 (2008).

28. Masoli, S. \& D’Angelo, E. Synaptic activation of a detailed Purkinje cell model predicts voltage-dependent control of burst-pause responses in active dendrites. Front. Cell Neurosci. 11, 278. https://doi.org/10.3389/fncel.2017.00278 (2017). 
29. Diwakar, S., Magistretti, J., Goldfarb, M., Naldi, G. \& D’Angelo, E. Axonal Na+ channels ensure fast spike activation and backpropagation in cerebellar granule cells. J. Neurophysiol. 101, 519-532. https://doi.org/10.1152/jn.90382.2008 (2009).

30. D'Angelo, E. et al. Theta-frequency bursting and resonance in cerebellar granule cells: Experimental evidence and modeling of a slow k+-dependent mechanism. J. Neurosci. 21, 759-770 (2001).

31. Solinas, S. et al. Computational reconstruction of pacemaking and intrinsic electroresponsiveness in cerebellar Golgi cells. Front. Cell Neurosci. 1, 2. https://doi.org/10.3389/neuro.03.002.2007 (2007).

32. Solinas, S. et al. Fast-reset of pacemaking and theta-frequency resonance patterns in cerebellar golgi cells: Simulations of their impact in vivo. Front. Cell Neurosci. 1, 4. https://doi.org/10.3389/neuro.03.004.2007 (2007).

33. Masoli, S., Solinas, S. \& D’Angelo, E. Action potential processing in a detailed Purkinje cell model reveals a critical role for axonal compartmentalization. Front. Cell Neurosci. 9, 47. https://doi.org/10.3389/fncel.2015.00047 (2015).

34. Masoli, S. et al. Single neuron optimization as a basis for accurate biophysical modeling: The case of cerebellar granule cells. Front. Cell. Neurosci. 11, https://doi.org/10.3389/fncel.2017.00071 (2017).

35. Masoli, S., Tognolina, M., Laforenza, U., Moccia, F. \& D’Angelo, E. Parameter tuning differentiates granule cell subtypes enriching transmission properties at the cerebellum input stage. Commun. Biol. https://doi.org/10.1038/s42003-020-0953-x (2020).

36. Lennon, W., Hecht-Nielsen, R. \& Yamazaki, T. A spiking network model of cerebellar Purkinje cells and molecular layer interneurons exhibiting irregular firing. Front. Comput. Neurosci. 8, 157. https://doi.org/10.3389/fncom.2014.00157 (2014).

37. Lennon, W., Yamazaki, T. \& Hecht-Nielsen, R. A model of in vitro plasticity at the parallel fiber-molecular layer interneuron synapses. Front. Comput. Neurosci. https://doi.org/10.3389/fncom.2015.00150 (2015).

38. De Zeeuw, C. et al. Spatiotemporal firing patterns in the cerebellum. Nat. Rev. Neurosci. https://doi.org/10.1038/nrn3011 (2011).

39. Arlt, C. \& Häusser, M. Microcircuit rules governing impact of single interneurons on purkinje cell output in vivo. Cell Rep. https ://doi.org/10.1016/j.celrep.2020.02.009 (2020).

40. Druckmann, S. et al. A novel multiple objective optimization framework for constraining conductance-based neuron models by experimental data. Front. Neurosci. 1, 7-18. https://doi.org/10.3389/neuro.01.1.1.001.2007 (2007).

41. Dean, P. \& Porrill, J. The cerebellum as an adaptive filter: A general model?. Funct. Neurol. 25, 173-180 (2010).

42. Alcami, P. \& Marty, A. Estimating functional connectivity in an electrically coupled interneuron network. Proc. Natl. Acad. Sci. USA https://doi.org/10.1073/pnas.1310983110 (2013).

43. Hines, M. \& Carnevale, N. Neuron: A tool for neuroscientists. Neuroscientist https://doi.org/10.1177/107385840100700207 (2001).

44. Nieus, T. et al. LTP regulates burst initiation and frequency at mossy fiber-granule cell synapses of rat cerebellum: experimental observations and theoretical predictions. J. Neurophysiol. 95, 686-699, https://doi.org/10.1152/jn.00696.2005 (2006)

45. Van Geit, W. et al. BluePyOpt: Leveraging open source software and cloud infrastructure to optimise model parameters in neuroscience. Front. Neuroinform. https://doi.org/10.3389/fninf.2016.00017 (2016).

46. Lu, H., Esquivel, A. V. \& Bower, J. M. 3D electron microscopic reconstruction of segments of rat cerebellar Purkinje cell dendrites receiving ascending and parallel fiber granule cell synaptic inputs. J. Comp. Neurol. 514, 583-594. https://doi.org/10.1002/ cne.22041 (2009).

47. He, Q. et al. Interneuron- and GABA(A) receptor-specific inhibitory synaptic plasticity in cerebellar Purkinje cells. Nat. Commun. https://doi.org/10.1038/ncomms8364 (2015).

48. Bidoret, C., Bouvier, G., Ayon, A., Szapiro, G. \& Casado, M. Properties and molecular identity of NMDA receptors at synaptic and non-synaptic inputs in cerebellar molecular layer interneurons. Front. Synaptic Neurosci. https://doi.org/10.3389/fnsyn .2015.00001 (2015).

49. Carter, A. \& Regehr, W. Prolonged synaptic currents and glutamate spillover at the parallel fiber to stellate cell synapse. J. Neurosci. https://doi.org/10.1523/JNEUROSCI.20-12-04423.2000 (2000).

50. Tsodyks, M., Pawelzik, K. \& Markram, H. Neural networks with dynamic synapses. Neural Comput. https://doi.org/10.1162/08997 6698300017502 (1998).

51. Santucci, D. \& Raghavachari, S. The effects of NR2 subunit-dependent NMDA receptor kinetics on synaptic transmission and CaMKII activation. PLoS Comput. Biol. https://doi.org/10.1371/journal.pcbi.1000208 (2008).

52. Nieus, T. R., Mapelli, L. \& D’Angelo, E. Regulation of output spike patterns by phasic inhibition in cerebellar granule cells. Front Cell Neurosci 8, 246. https://doi.org/10.3389/fncel.2014.00246 (2014).

53. Zitzler, E. \& Kunzli, S. Parallel Problem Solving from Nature - PPSN VIII | SpringerLink (Springer, Berlin, 2004).

54. Van Geit, W. Blue Brain Project. eFEL. https://github.com/BlueBrain/eFEL. (2015).

55. Gutfreund, Y., Yarom, Y. \& Segev, I. Subthreshold oscillations and resonant frequency in guinea-pig cortical neurons: Physiology and modelling. J. Physiol. https://doi.org/10.1113/jphysiol.1995.sp020611 (1995).

56. Rakic, P. Extrinsic cytological determinants of basket and stellate cell dendritic pattern in the cerebellar molecular layer. J. Comp. Neurol. https://doi.org/10.1002/cne.901460304 (1972).

57. Uylings, H., van Eden, C. \& Hofman, M. Morphometry of size/volume variables and comparison of their bivariate relations in the nervous system under different conditions. J. Neurosci. Methods https://doi.org/10.1016/0165-0270(86)90111-1 (1986).

58. Bok, S. Histonomy of the Cerebral Cortex (Elsevier, London, 1959).

59. Jacobs, B. et al. Comparative neuronal morphology of the cerebellar cortex in afrotherians, carnivores, cetartiodactyls, and primates. Front Neuroanat 8, 24. https://doi.org/10.3389/fnana.2014.00024 (2014).

60. Bao, J., Reim, K. \& Sakaba, T. Target-dependent feedforward inhibition mediated by short-term synaptic plasticity in the cerebellum. J. Neurosci. https://doi.org/10.1523/JNEUROSCI.0276-10.2010 (2010).

61. Dorgans, K. et al. Short-term plasticity at cerebellar granule cell to molecular layer interneuron synapses expands information processing. eLife https://doi.org/10.7554/eLife.41586 (2019).

62. Grangeray-Vilmint, A., Valera, A., Kumar, A. \& Isope, P. Short-term plasticity combines with excitation-inhibition balance to expand cerebellar purkinje cell dynamic range. J. Neurosci. https://doi.org/10.1523/JNEUROSCI.3270-17.2018 (2018).

63. Bower, J. M. \& Woolston, D. C. Congruence of spatial organization of tactile projections to granule cell and Purkinje cell layers of cerebellar hemispheres of the albino rat: Vertical organization of cerebellar cortex. J. Neurophysiol. 49, 745-766 (1983).

64. Nahir, B. \& Jahr, C. E. Activation of extrasynaptic NMDARs at individual parallel fiber-molecular layer interneuron synapses in cerebellum. J. Neurosci. 33, 16323-16333. https://doi.org/10.1523/JNEUROSCI.1971-13.2013 (2013).

65. Pouzat, C. \& Marty, A. Somatic recording of GABAergic autoreceptor current in cerebellar stellate and basket cells. J. Neurosci. https://doi.org/10.1523/JNEUROSCI.19-05-01675.1999 (1999).

66. Kondo, S. \& Marty, A. Synaptic currents at individual connections among stellate cells in rat cerebellar slices. J. Physiol. 509(Pt 1), 221-232. https://doi.org/10.1111/j.1469-7793.1998.221bo.x (1998).

67. Herzfeld, D. J., Kojima, Y., Soetedjo, R. \& Shadmehr, R. Encoding of action by the Purkinje cells of the cerebellum. Nature 526, 439-442. https://doi.org/10.1038/nature15693 (2015).

68. 68Koekkoek, S. et al. Cerebellar LTD and learning-dependent timing of conditioned eyelid responses. Science (New York, N.Y.) 301, https://doi.org/10.1126/science.1088383 (2003).

69. D’Angelo, E., De Filippi, G., Rossi, P. \& Taglietti, V. Synaptic excitation of individual rat cerebellar granule cells in situ: Evidence for the role of NMDA receptors. J Physiol 484 (Pt 2), 397-413 (1995).

70. Forti, L., Cesana, E., Mapelli, J. \& D’Angelo, E. Ionic mechanisms of autorhythmic firing in rat cerebellar Golgi cells. J Physiol 574, 711-729. https://doi.org/10.1113/jphysiol.2006.110858 (2006). 
71. Dykstra, S., Engbers, J. D. T., Bartoletti, T. M. \& Turner, R. W. J Physiol 594, 985-1003 (2016).

72. Moscato, L. et al. Long-lasting response changes in deep cerebellar nuclei in vivo correlate with low-frequency oscillations. Front Cell Neurosci 13, 84. https://doi.org/10.3389/fncel.2019.00084 (2019).

73. D’Angelo, E. et al. The cerebellar network: from structure to function and dynamics. Brain Res Rev 66, 5-15. https://doi. org/10.1016/j.brainresrev.2010.10.002 (2011).

74. Braitenberg, V., Heck, D. \& Sultan, F. The detection and generation of sequences as a key to cerebellar function: Experiments and theory. Behav. Brain Sci. 20, 1 (1997).

75. Kim, T. et al. Long-term optical access to an estimated one million neurons in the live mouse cortex. Cell Rep. https://doi. org/10.1016/j.celrep.2016.12.004 (2016).

76. Casali, S., Marenzi, E., Medini, C., Casellato, C. \& D’Angelo, E. Reconstruction and simulation of a Scaffold model of the cerebellar network. Front. Neuroinform. https://doi.org/10.3389/fninf.2019.00037 (2019).

77. Zhang, B. et al. Neuroligins sculpt cerebellar Purkinje-cell circuits by differential control of distinct classes of synapses. Neuron https://doi.org/10.1016/i.neuron.2015.07.020 (2015).

78. Gall, D. et al. Intracellular calcium regulation by burst discharge determines bidirectional long-term synaptic plasticity at the cerebellum input stage. J. Neurosci. 25, 4813-4822. https://doi.org/10.1523/JNEUROSCI.0410-05.2005 (2005).

79. D’Errico, A., Prestori, F. \& D’Angelo, E. Differential induction of bidirectional long-term changes in neurotransmitter release by frequency-coded patterns at the cerebellar input. J Physiol 587, 5843-5857. https://doi.org/10.1113/jphysiol.2009.177162 (2009).

80. D'Angelo, E. \& De Zeeuw, C. I. Timing and plasticity in the cerebellum: Focus on the granular layer. Trends Neurosci. 32, 30-40. https://doi.org/10.1016/j.tins.2008.09.007 (2009).

81. Ito, M. \& Kano, M. Long-lasting depression of parallel fiber-Purkinje cell transmission induced by conjunctive stimulation of parallel fibers and climbing fibers in the cerebellar cortex. Neurosci Lett 33, 253-258 (1982).

82. Lev-Ram, V., Wong, S. T., Storm, D. R. \& Tsien, R. Y. A new form of cerebellar long-term potentiation is postsynaptic and depends on nitric oxide but not cAMP. Proc Natl Acad Sci U S A 99, 8389-8393. https://doi.org/10.1073/pnas.122206399 (2002).

83. Salin, P., Malenka, R. \& Nicoll, R. Cyclic AMP mediates a presynaptic form of LTP at cerebellar parallel fiber synapses. Neuron https://doi.org/10.1016/s0896-6273(00)80099-9 (1996).

84. Coesmans, M., Weber, J. T., De Zeeuw, C. I. \& Hansel, C. Bidirectional parallel fiber plasticity in the cerebellum under climbing fiber control. Neuron 44, 691-700. https://doi.org/10.1016/j.neuron.2004.10.031 (2004).

85. Qiu, D. L. \& Knöpfel, T. Presynaptically expressed long-term depression at cerebellar parallel fiber synapses. Pflugers Arch 457, 865-875. https://doi.org/10.1007/s00424-008-0555-9 (2009).

86. Liu, S. J., Lachamp, P., Liu, Y., Savtchouk, I. \& Sun, L. Long-term synaptic plasticity in cerebellar stellate cells. Cerebellum 7, 559-562. https://doi.org/10.1007/s12311-008-0057-5 (2008).

87. Rancillac, A. \& Crépel, F. Synapses between parallel fibres and stellate cells express long-term changes in synaptic efficacy in rat cerebellum. J Physiol 554, 707-720. https://doi.org/10.1113/jphysiol.2003.055871 (2004).

88. Bender, V. A., Pugh, J. R. \& Jahr, C. E. Presynaptically expressed long-term potentiation increases multivesicular release at parallel fiber synapses. J Neurosci 29, 10974-10978. https://doi.org/10.1523/JNEUROSCI.2123-09.2009 (2009).

89. Kawaguchi, S. Y. \& Hirano, T. Sustained structural change of GABA(A) receptor-associated protein underlies long-term potentiation at inhibitory synapses on a cerebellar Purkinje neuron. J Neurosci 27, 6788-6799. https://doi.org/10.1523/JNEUROSCI.198107.2007 (2007).

90. Kano, M., Rexhausen, U., Dreessen, J. \& Konnerth, A. Synaptic excitation produces a long-lasting rebound potentiation of inhibitory synaptic signals in cerebellar Purkinje cells. Nature 356, 601-604. https://doi.org/10.1038/356601a0 (1992).

91. Hirano, T. \& Kawaguchi, S. Regulation and functional roles of rebound potentiation at cerebellar stellate cell-Purkinje cell synapses. Front. Cell. Neurosci. https://doi.org/10.3389/fncel.2014.00042 (2014).

92. Mapelli, L., Pagani, M., Garrido, J. A. \& D’Angelo, E. Integrated plasticity at inhibitory and excitatory synapses in the cerebellar circuit. Front Cell Neurosci 9, 169. https://doi.org/10.3389/fncel.2015.00169 (2015).

93. Gao, Z., van Beugen, B. J. \& De Zeeuw, C. I. Distributed synergistic plasticity and cerebellar learning. Nat Rev Neurosci 13, 619-635. https://doi.org/10.1038/nrn3312 (2012).

94. D’Angelo, E. The organization of plasticity in the cerebellar cortex: from synapses to control. Prog Brain Res 210, 31-58. https ://doi.org/10.1016/B978-0-444-63356-9.00002-9 (2014).

95. Casali, S., Tognolina, M. \& D’Angelo, E. Cellular-resolution mapping uncovers spatial adaptive filtering at the cerebellum input stage. BioRxiv. https://doi.org/10.1101/2020.03.14.991794 (2020).

96. Diwakar, S., Lombardo, P., Solinas, S., Naldi, G. \& D’Angelo, E. Local field potential modeling predicts dense activation in cerebellar granule cells clusters under LTP and LTD control. PLoS ONE 6, e21928. https://doi.org/10.1371/journal.pone.0021928 (2011).

97. Bower, J. M. The organization of cerebellar cortical circuitry revisited: implications for function. Ann N Y Acad Sci 978, 135-155. https://doi.org/10.1111/j.1749-6632.2002.tb07562.x (2002).

98. Ros, H., Sachdev, R. N., Yu, Y., Sestan, N. \& McCormick, D. A. Neocortical networks entrain neuronal circuits in cerebellar cortex. J Neurosci 29, 10309-10320. https://doi.org/10.1523/JNEUROSCI.2327-09.2009 (2009).

99. Courtemanche, R., Robinson, J. C. \& Aponte, D. I. Linking oscillations in cerebellar circuits. Front Neural Circuits 7, 125. https ://doi.org/10.3389/fncir.2013.00125 (2013).

100. Casali, S. et al. Reconstruction and simulation of a Scaffold model of the cerebellar network. Front. Neuroinform. https://doi. org/10.3389/fninf.2019.00037 (2019).

\section{Author contributions}

M.F.R. has fully developed the SC models and the corresponding simulation analysis and text. F.L. performed the patch-clamp recordings. S.M. supervised modeling and simulations with Purkinje cells. D.S.P. and A.M. performed the morphological SC reconstructions. F.P. supervised experiments, analyzed data and wrote the first version of the paper. E.D. coordinated the whole work, participated to data analysis and model simulations and wrote the final version of the paper.

\section{Funding}

This project/research received funding from the European Union's Horizon 2020 Framework Programme for Research and Innovation under the Framework Partnership Agreement No. 650003 (HBP FPA) to ED and AM/J DeFelipe. This research was supported by the HBP Brain Simulation Platform, funded from the European Union's Horizon 2020 Framework Programme for Research and Innovation under the Specific Grant Agreement No. 785907 (Human Brain Project SGA2) and by the EBRAINS research infrastructure, funded from the European Union's Horizon 2020 Framework Programme for Research and Innovation under the Specific Grant Agreement No. 945539 (Human Brain Project SGA3) to ED.This research was also supported by the MNL Project "Local 
Neuronal Microcircuits" of the Centro Fermi (Rome, Italy) to ED. Model optimizations and simulations were performed on the Piz Daint supercomputer (CSCS-Lugano) with a specific grant (PRACE special proposal 03).

\section{Competing interests}

The authors declare no competing interests.

\section{Additional information}

Supplementary Information The online version contains supplementary material available at https://doi. org/10.1038/s41598-021-83209-w.

Correspondence and requests for materials should be addressed to E.D.

Reprints and permissions information is available at www.nature.com/reprints.

Publisher's note Springer Nature remains neutral with regard to jurisdictional claims in published maps and institutional affiliations.

(c) (i) Open Access This article is licensed under a Creative Commons Attribution 4.0 International License, which permits use, sharing, adaptation, distribution and reproduction in any medium or format, as long as you give appropriate credit to the original author(s) and the source, provide a link to the Creative Commons licence, and indicate if changes were made. The images or other third party material in this article are included in the article's Creative Commons licence, unless indicated otherwise in a credit line to the material. If material is not included in the article's Creative Commons licence and your intended use is not permitted by statutory regulation or exceeds the permitted use, you will need to obtain permission directly from the copyright holder. To view a copy of this licence, visit http://creativecommons.org/licenses/by/4.0/.

(C) The Author(s) 2021 